\title{
Oxidant Mechanisms in Renal Injury and Disease
}

\author{
Brian B. Ratliff,, ${ }^{1,2}$ Wasan Abdulmahdi, Rahul Pawar, and Michael S. Wolin ${ }^{2}$
}

\begin{abstract}
Significance: A common link between all forms of acute and chronic kidney injuries, regardless of species, is enhanced generation of reactive oxygen species (ROS) and reactive nitrogen species (RNS) during injury/ disease progression. While low levels of ROS and RNS are required for prosurvival signaling, cell proliferation and growth, and vasoreactivity regulation, an imbalance of ROS and RNS generation and elimination leads to inflammation, cell death, tissue damage, and disease/injury progression. Recent Advances: Many aspects of renal oxidative stress still require investigation, including clarification of the mechanisms which prompt ROS/ RNS generation and subsequent renal damage. However, we currently have a basic understanding of the major features of oxidative stress pathology and its link to kidney injury/disease, which this review summarizes. Critical Issues: The review summarizes the critical sources of oxidative stress in the kidney during injury/ disease, including generation of ROS and RNS from mitochondria, NADPH oxidase, and inducible nitric oxide synthase. The review next summarizes the renal antioxidant systems that protect against oxidative stress, including superoxide dismutase and catalase, the glutathione and thioredoxin systems, and others. Next, we describe how oxidative stress affects kidney function and promotes damage in every nephron segment, including the renal vessels, glomeruli, and tubules. Future Directions: Despite the limited success associated with the application of antioxidants for treatment of kidney injury/disease thus far, preventing the generation and accumulation of ROS and RNS provides an ideal target for potential therapeutic treatments. The review discusses the shortcomings of antioxidant treatments previously used and the potential promise of new ones. Antioxid. Redox Signal. 25, 119-146.
\end{abstract}

\section{Introduction}

$\mathbf{T}$ ODAY, THE PREVALENCE of acute kidney injury (AKI) in the United States ranges from $1 \%$ (total population) up to $7.1 \%$ (total hospitalized patients) $(143,199)$, with as many as two-thirds of ICU patients developing AKI, as defined by the RIFLE classification (115). Patients with AKI oftentimes face a grim fate with mortality rates ranging from $10 \%$ to $80 \%$, depending on the patient population $(49,116,161$, 283). These percentages have been steadily increasing in the United States over the past few decades. Furthermore, in 2014, the Centers for Disease Control and Prevention (CDC) reported that more than $10 \%$ of adults in the United States have chronic kidney disease (CKD), with $30 \%$ of individuals over the age of 65 experiencing some form of kidney failure. Adults with diabetes or hypertension are at particularly high risk to develop CKD. Approximately one of every three adults with diabetes and one of every five adults with hypertension develop CKD (1). Unfortunately, treatment of kidney failure has not progressed in the last 70 years since the introduction of dialysis. Part of the problem of developing new and more effective therapeutic treatments is that we still do not completely understand all of the molecular mechanisms that are responsible for progressing kidney failure.

A patient who undergoes some form of AKI has a high risk for developing CKD within 10-15 years. The causes for AKI are variable, as are the causes for CKD. While AKI is typically the result of an acute transient episode of systemic damage, $\mathrm{CKD}$ is brought about usually due to genetic predisposition, syndrome, or illness that leads to secondary kidney injury or a previous bout of AKI. Regardless, in every case of impaired kidney function, either acute or chronic, oxidative stress plays a role in renal damage and offers a potential target for therapeutic intervention. In fact, oxidative stress has been linked to

Departments of ${ }^{1}$ Medicine and ${ }^{2}$ Physiology, Renal Research Institute, New York Medical College, Valhalla, New York. 
the pathogenesis of a variety of diseases, such as cardiovascular disease, atherosclerosis, hypertension, cancer, diabetes, arthritis neurodegenerative diseases (i.e., Alzheimer's and Parkinson's disease), and aging (300).

Oxidative stress is characterized by increases in reactive oxygen species (ROS) and/or reactive nitrogen species (RNS). While many reports exist that indicate ROS and RNS are elevated in both human and animal models of kidney injury (including cardiovascular injury) due to various etiologies, few definitive reports exist that directly define the factors and mechanisms responsible for enhancement of ROS and RNS in the kidney, the signaling mechanisms these oxidative species stimulate to promote damage, and the effect oxidative stress has on endogenous antioxidant systems that protect the kidney from damage and subsequently maintain normal kidney function. Due to the commonality of enhanced oxidative stress in all forms of kidney injury and disease, a broader understanding of these phenomena would be beneficial for the design of effective therapeutic strategies against kidney failure. The lack of in vivo reports is not necessarily due to an absence in effort, but rather the challenges in studying ROS and RNS directly in whole animal and human models due to the specific cellular localizations and active metabolism or instability of ROS and RNS.

While much is left to investigate regarding oxidative stress during $\mathrm{AKI}$ and $\mathrm{CKD}$, this review will attempt to summarize what is currently known about ROS and RNS in the kidney by drawing from in vitro and in vivo (animal and human models) research. The beginning of the review will briefly describe the specific ROS and RNS that are responsible for oxidative stress. This section is kept brief since numerous reviews have been written on the subject. Next, we describe the sources of oxidative stress in the kidney and the antioxidant systems that are responsible for the organ's protection against pathological generation of ROS and RNS. Oxidative stress both directly and indirectly affects all facets of the kidney, including vascular reactivity and renal hemodynamics, glomerular filtration, and tubular reabsorption and secretion in all nephron segments. During injury or disease, oxidative stress signaling alters all of these processes and promotes prodamage pathways that lead to cellular apoptosis, necrosis, altered gene expression, progression of tissue damage, promotion of fibrosis, and abnormal kidney function. The review will summarize what is currently known with regard to these aspects in the kidney during both AKI and CKD. We conclude by describing some of the current antioxidative therapeutic treatments that have been tested in animals and humans and potential therapeutic treatments that may hold promise for future exploration.

\section{The Players of Oxidative Stress}

The one-electron reduction of molecular oxygen results in the generation of superoxide anion $\left(\mathrm{O}_{2}-\right)$ and this leads to a variety of ROS (206) associated with processes described in Table 1. Superoxide is generated by several oxidase enzymes and by components of the mitochondrial electron transport chain. Superoxide anion has rather selective reactive properties and poorly diffuses across biological membranes due to it primarily being transported through anion channels. Superoxide anion also undergoes dismutation (either spontaneously or by enzymatic catalysis) to form another ROS, the nonradical species-hydrogen peroxide $\left(\mathrm{H}_{2} \mathrm{O}_{2}\right)$. Hydrogen peroxide can also be formed by direct reduction of oxygen $\left(\mathrm{O}_{2}\right)$ by oxidases. Unlike superoxide, hydrogen peroxide has membrane transport properties similar to water and this enables it to diffuse across membranes and influence regulatory systems in other cellular compartments or nearby cells.

Superoxide releases $\mathrm{Fe}^{3+}$ from iron-sulfur proteins and ferritin, thus promoting generation of additional ROS. For example, peroxides react with various forms of Fe either bound to proteins (e.g., heme) or small molecular weight molecules to generate additional highly reactive oxidant species. One potential species is the hydroxyl radical $(\cdot \mathrm{OH})$, which is readily generated by the Fenton reaction of peroxide with $\mathrm{Fe}^{2+}$. Hydroxyl radicals attack and react with almost all cellular constituents and generate additional reactive free radicals. In addition, reactive species resembling the hydroxyl radical can also be formed from decomposition of RNS such as peroxynitrite, which is generated from the very efficient reaction of superoxide with nitric oxide $(\cdot \mathrm{NO})$. Reactive species resembling hydroxyl react with cellular constituents, such as unsaturated fatty acids in lipids and nucleic acids, and promote lipid peroxidation and damage of mitochondrial and nuclear DNA.

Hypochlorous acid $(\mathrm{HOCl})$ is another ROS, which is lipid soluble and extremely reactive. Hypochlorous acid is formed by phagocyte cell myeloperoxidase when it metabolizes hydrogen peroxide. In the presence of nitrite, myeloperoxidase reacts to generate highly reactive species (such as nitrogen dioxide), which behave similar to peroxynitrite in promoting tyrosine nitration and other reactions. Low levels of ROS have important signaling roles in cells, but as their levels increase, ROS actively participate in pathophysiology processes, including induction of various forms of cell death.

RNS derived from the free radical nitric oxide (including nitrogen dioxide $\left[\cdot \mathrm{NO}_{2}\right]$, nonradical peroxynitrite $\left[\mathrm{ONOO}^{-}\right]$, and other RNS) are additional factors in renal pathophysiology. Nitric oxide is formed by the various isoforms of nitric oxide synthase (NOS) that use L-arginine, oxygen, and other cofactors, including tetrahydrobiopterin, to produce nitric oxide. The free radical nitric oxide is very selective in its reactive properties and it can go on to form other RNS, including peroxynitrite, which is formed by reaction of nitric oxide with superoxide. RNS are often observed to interact with cellular components, including thiol groups and unsaturated fatty acids, to promote regulation through processes such as thiol (RSH) or lipid oxidation or other modifications, including nitrosation (RSNO) or nitration $\left(\mathrm{RSNO}_{2}\right)$. While some of these interactions are part of signaling, as RNS levels increase, they actively contribute to pathological processes in the cardiovascular and renal systems.

\section{Renal Antioxidants}

\section{Superoxide dismutase}

There are multiple antioxidant systems described in Table 2 that attempt to protect kidney tissues and cells from ROS or RNS-induced oxidative stress. The first intrinsic enzymes that combat oxidative stress are the superoxide dismutase (SOD) isoforms. SOD catalyzes the dismutation of superoxide into oxygen and hydrogen peroxide $(178,179)$. All three SOD isoforms are normally found in the kidney and are localized to the mitochondria, cytoplasm, and extracellular space where it is anchored by its heparin binding domain (74, 
Table 1. Properties and Actions of Reactive Oxygen and Nitric Oxide-Derived Species Potentially Contributing to the Development of Renal Disease

\begin{tabular}{|c|c|c|}
\hline Species & Origin and properties & Biological actions \\
\hline $\begin{array}{l}\text { Nitric } \\
\quad \text { oxide (NO) }\end{array}$ & $\begin{array}{l}\text { NOS enzymes generate NO in amounts that } \\
\text { participate in beneficial physiological signaling } \\
\text { mechanisms, primarily as a result of the } \\
\text { regulation of nNOS (NOS1) and eNOS (NOS3) } \\
\text { activity. Inflammatory conditions promote the } \\
\text { induction of iNOS (NOS2) expression and the } \\
\text { generation of much larger amounts of NO, } \\
\text { which participate in modulating aspects of } \\
\text { inflammatory processes. NO is a dissolved gas, } \\
\text { which binds to ferrous heme sites and readily } \\
\text { reacts with some specific biological molecules. }\end{array}$ & $\begin{array}{l}\text { At low n } M \text { levels, NO binds to soluble guanylate } \\
\text { cyclase and cytochrome c oxidase to regulate } \\
\text { cGMP production and mitochondrial } \\
\text { respiration, respectively. } \\
\text { As NO levels increase, it potentially interacts } \\
\text { with sites such as bound iron or produces } \\
\text { reactive NO-derived species, which can } \\
\text { nitrosate thiols. } \\
\text { When NO levels increase to the range of local } \\
\text { concentrations of SOD enzymes, it competes } \\
\text { with SOD for the scavenging of superoxide, } \\
\text { and this reaction generates peroxynitrite. } \\
\text { While NO is removed by reaction with } \\
\text { hemoglobin and other processes, it also } \\
\text { decomposes to generate nitrite. }\end{array}$ \\
\hline $\begin{array}{l}\text { Superoxide } \\
\quad \text { anion }\left(\mathrm{O}_{2} \cdot{ }^{-}\right)\end{array}$ & $\begin{array}{l}\text { Metabolism of molecules such as NADPH, } \\
\text { NADH, and xanthine by various oxidase } \\
\text { enzymes regulated or recruited by } \\
\text { pathophysiological processes donates an } \\
\text { electron to oxygen to from superoxide anion. } \\
\text { The activities of superoxide scavengers, such } \\
\text { as SOD, and molecules that superoxide reacts } \\
\text { with in regions it is generated determine its } \\
\text { biological actions. The levels of SOD appear to } \\
\text { keep superoxide levels in the pM concentration } \\
\text { range under physiological conditions. }\end{array}$ & $\begin{array}{l}\text { The metabolism of superoxide by SOD enzymes } \\
\text { generates hydrogen peroxide in amounts that } \\
\text { are important in physiological processes such } \\
\text { as oxygen sensing. } \\
\text { The scavenging of NO appears to be the most } \\
\text { potent biological action of superoxide. } \\
\text { Disruption of iron-sulfur centers and reactions } \\
\text { with catecholamines are some additional } \\
\text { actions of superoxide as its levels increase in } \\
\text { pathophysiological processes. }\end{array}$ \\
\hline $\begin{array}{l}\text { Hydrogen } \\
\text { peroxide } \\
\left(\mathrm{H}_{2} \mathrm{O}_{2}\right)\end{array}$ & $\begin{array}{l}\text { Peroxide generation from superoxide metabolism } \\
\text { by SOD, the activities of some oxidases, and } \\
\text { release from mitochondria are major } \\
\text { contributors to the regulation of many } \\
\text { signaling mechanisms as a result of peroxide } \\
\text { being metabolized by various peroxide- } \\
\text { consuming enzymes. When more elevated } \\
\text { levels of peroxide are formed, it reacts with } \\
\text { sites such as bound ferrous iron, causing the } \\
\text { generation of highly reactive species } \\
\text { resembling hydroxyl radical. }\end{array}$ & $\begin{array}{l}\text { Peroxide metabolism by peroxidases, which } \\
\text { oxidize thiols such as GSH or Trx, promotes } \\
\text { signaling processes through these thiol redox } \\
\text { systems at low n } M \text { levels of peroxide. } \\
\text { The diffusion and transport properties of peroxide } \\
\text { allow it to be a versatile signaling molecule } \\
\text { between cells and subcellular compartments. } \\
\text { The metabolism of peroxide by specific heme } \\
\text { peroxidases in the presence of nitrite or } \\
\text { chloride, respectively, can generate nitrogen } \\
\text { dioxide or hypochlorous acid. }\end{array}$ \\
\hline $\begin{array}{l}\text { Peroxynitrite } \\
\left(\mathrm{ONOO}^{-}\right) \\
\text {and nitrogen } \\
\text { dioxide }\left(\mathrm{NO}_{2}\right)\end{array}$ & $\begin{array}{l}\text { The reaction of superoxide anion with NO } \\
\text { generates peroxynitrite. Nitrogen dioxide is } \\
\text { formed by the spontaneous decomposition of } \\
\text { peroxynitrite and from the metabolism of } \\
\text { nitrite by heme peroxidase enzymes when they } \\
\text { are consuming peroxide. These reactive species } \\
\text { participate in oxidizing, nitrating, or modifying } \\
\text { sites such as protein thiols and tyrosine } \\
\text { residues and nucleic acids. }\end{array}$ & $\begin{array}{l}\text { The oxidation or nitration of thiols by these RNS } \\
\text { activates a variety of signaling mechanisms, } \\
\text { sometimes targeting processes are also } \\
\text { activated by the actions of peroxide. } \\
\text { The reaction of RNS with unsaturated fatty acids } \\
\text { produces oxidized and nitrated fatty acids, } \\
\text { which seem to have a variety of biological } \\
\text { actions. } \\
\text { Peroxynitrite appears to be a very potent } \\
\text { irreversible inhibitor of mitochondrial } \\
\text { respiration through disrupting iron-sulfur } \\
\text { centers. }\end{array}$ \\
\hline $\begin{array}{l}\text { Other reactive } \\
\text { species }\end{array}$ & $\begin{array}{l}\text { Highly reactive iron-catalyzed peroxide and } \\
\text { peroxynitrite-derived species with reactivities } \\
\text { resembling hydroxyl radical promote processes } \\
\text { such as lipid peroxidation, nucleic acid } \\
\text { damage, oxidation of multiple amino acids, and } \\
\text { other oxidant actions associated with tissue } \\
\text { injury. Hypochlorous acid generation by } \\
\text { inflammatory cell myloperoxidase can produce } \\
\text { chloroamines as a result of reacting with } \\
\text { amines. }\end{array}$ & $\begin{array}{l}\text { Multiple reactive molecules such as carbonyls, } \\
\text { unsaturated aldehydes, and nitrated lipids can } \\
\text { be produced by highly reactive oxygen and } \\
\text { NO-derived species. } \\
\text { At low levels of oxidant stress, these molecules } \\
\text { have chemical reactions that can activate } \\
\text { signaling processes. As the level of oxidant } \\
\text { stress increases, these species participate in } \\
\text { promoting the various forms of cell death that } \\
\text { are observed. }\end{array}$ \\
\hline
\end{tabular}

cGMP, cyclic guanosine monophosphate; iNOS, inducible nitric oxide synthase; nNOS, neuronal nitric oxide synthase; RNS, reactive nitrogen species; SOD, superoxide dismutase. 
Antioxidant

system

SODs peroxidases

Catalase is a heme-containing enzyme found in regions such as peroxisomes and cytosol. It converts hydrogen peroxide into oxygen and water.

GSH peroxidases and peroxiredoxins reduce peroxide to water by oxidizing GSH and Trx, respectively. These enzymes are found in multiple cellular regions, and they both lower peroxide and regulate signaling mechanisms in the cellular regions they are located.

Heme peroxidases are enzymes, which consume peroxide in a manner that is often associated with promoting other biological actions.

Physiological cofactors
Cysteine (Cys) is an amino acid used to generate GSH and hydrogen sulfide.

GSH is the thiol present in highest concentration in the intracellular environment. It is used for the consumption of peroxides by GSH peroxidases. Its redox status is controlled by NADPHdependent GSH reductases.

Trxs are cofactors for the consumption of peroxide by peroxidredoxins and their redox is controlled by NADPH-dependent Trx reductases.

NADPH has multiple metabolic regulatory roles, including maintaining the redox of GSH and Trx, and being a source of electrons for nitric oxide biosynthesis and superoxide or peroxide production by various NADPH oxidases.
Biological actions

SOD1 suppresses the scavenging of NO by superoxide in the intracellular environment and it maintains the generation of hydrogen peroxide in cellular regions where it is located.

SOD2 has a major influence on peroxide generation and release from the mitochondrial matrix. It also protects SOD2 and iron-sulfur centers from disruption by superoxide-derived peroxynitrite generation.

SOD3 is an important factor in the protection of NO from reaction with superoxide in the extracellular environment and in the conversion of extracellular superoxide into peroxide.

Catalase does not require cofactors for the consumption of peroxide, enabling it to be a primary consumer of peroxide under conditions where the reducing thiol-related cofactors for other peroxidases become depleted by their oxidation.

GSH peroxidases and peroxiredoxins are major consumers of the low levels of peroxide generated in most subcellular environments where they are localized. While peroxide is consumed by these enzymes, the oxidized forms of GSH and Trx that are generated have major roles in driving multiple signaling processes through modulating the redox states of thiols on proteins that control signaling processes.

Heme peroxidases have roles in biological regulation through processes, such as peroxide stimulating the generation of prostaglandins $G_{2}$ and $\mathrm{H}_{2}$ by cyclooxygenase, and by promoting hypochlorous acid and nitrogen dioxide generation by myloperoxidase.

Cellular Cys redox may have a major role in controlling processes influenced by extracellular Cys redox, which include its use to consume peroxides by an extracellular-circulating form of GSH peroxidase. Cys may also directly participate in the transfer of NO between nitrosated thiols (RSNO).

The local concentration of GSH and its redox status regulate the efficiency of peroxide consumption and the redox of specific protein Cys through enzymes such as glutaredoxin. It also binds a variety of transition metals and reactive chemical species in ways that may shift their toxic actions toward signaling mechanisms.

The local concentration of Trx and its redox status also regulates the efficiency of peroxide consumption and the redox of specific protein Cys by direct reactions with reduced or oxidized Trx.

The redox status of NADPH in subcellular regions has major effects on controlling the levels of ROS generation, efficiency of peroxide metabolism, and the redox status of protein thiols through its influence of GSH and Trx redox. Thus, many regulatory systems participating in physiological function, adaptation, pathophysiology, and cell death are controlled by the way metabolic control of NADPH redox influences the functions of these other redox-associated systems. 
TABLE 2. (CONTINUED)

\begin{tabular}{|c|c|c|}
\hline $\begin{array}{l}\text { Antioxidant } \\
\text { system }\end{array}$ & Components and properties & Biological actions \\
\hline $\mathrm{HO}$ & $\begin{array}{l}\text { HO- } 1 \text { is induced under oxidant conditions and it } \\
\text { functions to remove heme, resulting in } \\
\text { generation of carbon monoxide, bilirubin (via } \\
\text { biliverdin), and iron. }\end{array}$ & $\begin{array}{l}\text { HO- } 1 \text { consumption of heme removes a catalyst, } \\
\text { which can participate in the generation of highly } \\
\text { reactive species upon its reaction with peroxide. } \\
\text { The HO- } 1 \text { reaction also appears to be protective } \\
\text { against oxidant stress by signaling actions of } \\
\text { carbon monoxide and bilirubin, by antioxidant } \\
\text { actions of bilirubin, and by creating conditions } \\
\text { that promote expression of additional antioxidant } \\
\text { defense mechanisms. }\end{array}$ \\
\hline \multirow[t]{3}{*}{$\begin{array}{l}\text { Dietary } \\
\text { antioxidants }\end{array}$} & $\begin{array}{l}\text { Ascorbate redox is maintained by various } \\
\text { components of cellular redox systems and it } \\
\text { directly reacts with oxidized forms of enzymes } \\
\text { and other molecules (including some free } \\
\text { radicals). }\end{array}$ & $\begin{array}{l}\text { Ascorbate has roles as a cofactor for some } \\
\text { enzymatic reactions and its chemical reaction } \\
\text { properties allow it to maintain the reduced forms } \\
\text { of molecules such as tetrahydrobiopterin and } \\
\text { tocopherol in ways that enable the maintenance of } \\
\text { NO biosynthesis and participate in a variety of } \\
\text { antioxidant-type defense mechanisms. }\end{array}$ \\
\hline & $\begin{array}{l}\text { Tocopherol is a hydrophobic molecule that } \\
\text { scavenges many free radicals. }\end{array}$ & $\begin{array}{l}\text { Tocopherol functions to attenuate free radical } \\
\text { propagation reactions that participate in processes } \\
\text { such as lipid peroxidation. }\end{array}$ \\
\hline & $\begin{array}{l}\text { Dietary antioxidants are numerous substances in } \\
\text { our diet, which influence antioxidant defense } \\
\text { mechanisms through scavenging free radicals } \\
\text { and reactive species. Some of these substances } \\
\text { may also directly influence the enzymatic } \\
\text { generation of ROS and NO. }\end{array}$ & $\begin{array}{l}\text { Dietary antioxidants clearly have actions that } \\
\text { enhance regulation through NO and decrease lipid } \\
\text { peroxidation reactions and the actions of reactive } \\
\text { species formed in biological systems, and these } \\
\text { actions may slow aspects of aging processes. } \\
\text { However, therapeutic approaches, which directly } \\
\text { target systems participating in disease processes } \\
\text { through mechanisms usually not related to their } \\
\text { antioxidant properties, often have more dominant } \\
\text { effects in the treatment of oxidant components of } \\
\text { disease processes. }\end{array}$ \\
\hline
\end{tabular}

GSH, glutathione; HO-1, heme oxygenase 1; ROS, reactive oxygen species; Trx, thioredoxin.

$209,210,216,294,295,337)$. Of the SOD isoforms, manganese SOD (SOD2) is present in the mitochondria, with copper/zinc SOD (SOD1 and SOD3) in the cytosol and the extracellular space, respectively $(178,179)$. The SOD1 isoform accounts for up to $80 \%$ of total SOD activity in the mammalian kidney (177), but only approximately one-third of SOD activity in the renal vessels, which prevents interruption of NO signaling (30). Interestingly, despite the imbalance with SOD1 accounting for the bulk of SOD activity in the kidneys, ablation of SOD2 in mice results in a dramatically more severe pathological phenotype compared with SOD1 ablation [reviewed by Schieber and Chandel (271)]. This highlights the importance of where in the cell ROS and RNS are generated and indicates that oxidative stress generated by the mitochondria plays a vital role in the pathogenesis of kidney disease and injury.

While there has been reported species-dependent variability in the localization of where each of the SOD isoforms is found within the kidney, in general, SOD activity in the kidney is similar in human, pig, sheep, cow, rabbit, and mouse (177). SOD has been reported in the cortical and juxtamedullary proximal tubule, the thick ascending limb, and in vascular smooth muscle cells (VSMCs) of renal blood vessels, with reduced activity in the medulla and glomeruli of rodents and canines (73, 216, 294, 295). However, despite minimal SOD activity in the renal medulla, SOD inhibition results in enhanced ROS in the kidneys, an effect that consequently reduces medullary blood flow, sodium excretion, and glomerular filtration while potentially inducing hypertension in rats $(170,171,334)$.

\section{Other antioxidants}

After SOD generates hydrogen peroxide from superoxide, peroxidases and catalase then convert hydrogen peroxide into oxygen and/or water. Catalase is present in all aerobic cells with elevated expression in the kidney (56). Catalase plays a critical role in reducing ROS and preventing lipid peroxidation. Catalase deficiency results in accumulation of mitochondrial ROS, an effect that leads to functional impairment of mitochondria (124). Furthermore, lipopolysaccharide (LPS)induced loss of catalase activity was demonstrated to significantly aggravate kidney damage in a mouse model of endotoxemia (302) [see review by Vasko and Goligorsky (301)].

Other vitally important defenses include the glutathione and the thioredoxin peroxidase systems. The enzymes of the glutathione and thioredoxin systems are distributed throughout the cell, including in the mitochondria, cytoplasm, and nucleus $(66,211)$. The glutathione and thioredoxin systems have been implicated in both the regulation of cellular redox and in many signaling mechanisms, controlling processes such as DNA synthesis, cell proliferation, and apoptosis (80). 
It has been reported that in addition to reduced SOD and catalase levels, glutathione is also diminished in a rat model of diabetic nephropathy (35) and in CKD patients $(32,215,282)$. Conversely, enhancement of catalase and glutathione has been shown to provide resistance against hydrogen peroxide in renal tubular epithelial cells (95). Some of the other factors that act as antioxidants influencing renal function include ascorbic acid (vitamin C), tocopherol (vitamin E), cysteine $(55,132)$, and the most sensitive indicator of cellular stress, heme oxygenase-1 (HO-1) (239).

While antioxidants play a critical role in maintaining cellular and tissue physiological and pathophysiological homeostasis associated with preventing accumulation of ROS and RNS, when their neutralizing ability is exceeded by oxidative stress then consequently pathological tissue damage ensues. For instance, dysregulation of antioxidants, particularly catalase and peroxidases, results in the accumulation of hydrogen peroxide, which can react with transition metals to subsequently form highly reactive and damaging species with reactivities, such as the hydroxyl radical. Furthermore, studies indicate the overproduction of superoxide, primarily by NADPH oxidase and mitochondria, and reduced superoxide metabolism by SOD and other antioxidants, can initiate or potentiate the development of hypertension (8). For example, it has been shown that during the onset of hypertension, patients have $7 \%$ lower antioxidant capacity, including decreased erythrocyte catalase content and enhanced oxidation of low-density lipoproteins (LDLs) $(45,266)$. As hypertension progresses, the antioxidant systems in these patients continue to falter due to reduced levels of SOD, glutathione peroxidase, and catalase $(249,263,285)$, resulting in the development of renal damage. At this point, NADPH oxidase-induced superoxide and ROS production is elevated in VSMCs of renal resistance arteries and in infiltrating leukocytes (182, 314, 331), causing increased plasma asymmetric dimethylarginine and lipid peroxidation (314). As the effects continue to mount, kidney damage progresses and kidney function wanes.

\section{Renal Sources of Oxidative Stress}

The role of ROS and RNS is considered a critical factor involved in initiation and progression of various mammalian kidney diseases and injuries, including diabetic nephropathy, hypertension-related kidney injury, ischemia-reperfusion injury (IRI), toxic-induced nephropathy, and several forms of inflammatory syndromes $(29,75,148,278,297)$. There is generation of ROS and RNS in both renal tubular and vascular cells during numerous tissue and cellular stresses. In the kidney and vascular systems, there are many sources of ROS and RNS that occur during both normal and pathological states, but the major sources of oxidative stress in the kidney come from NADPH oxidase and mitochondria generation $(12,27,213,244)$. It is important to point out that low levels of ROS and RNS are important for normal redox signaling that promotes cell survival, proliferation and growth, and vasoreactivity in the kidney, while also providing cells with a sensor for hypoxia. However, as cells and tissues are stressed, the balance between ROS and RNS generation and elimination is lost due to upregulated ROS/RNS formation and/or reduced antioxidant activity, resulting in the accumulation of these molecules. As ROS and RNS levels are increased, cell damage occurs and tissue function is impaired.

\section{NADPH oxidase ROS}

NADPH oxidases, along with the mitochondria, are the major producers of superoxide and are the principal sources of abnormal cellular signaling $(205,236,262)$. As NADPH oxidase transfers electrons from NADPH, they react with oxygen to form superoxide, which is usually rapidly converted to hydrogen peroxide. All of the components necessary for NADPH oxidase to function are present in the kidney, including the presence of four different isoforms of this oxidase-NOX1, NOX2, NOX4, and NOX5 $(8,33,112)$. The expression of these different NADPH oxidase isoform components has been observed throughout the cortex and medulla of the mammalian (including human) kidney, including in the mesangium $(97,136,184,190)$, proximal convoluted tubules, distal convoluted tubules, collecting duct, macula densa $(17,77,139,217,281,309,322)$, endothelium, and VSMCs (8).

NADPH oxidase is localized in the plasma membrane and generates superoxide for redox signaling for processes such as cell proliferation and interaction with the immune system that includes directing phagocytotic killing of invading microbes (168). Of the NADPH oxidase isoforms in the kidney, NOX4 is expressed the highest (90), producing large amounts of hydrogen peroxide constitutively (296). It has been suggested that the NOX4 isoform of NADPH oxidase is also localized in the mitochondria of the rat kidney cortex. This location would allow superoxide generated by NADPH oxidase to directly trigger mitochondrial generation of ROS (21). NADPH oxidase activity (including induction of NOX2 expression) can be stimulated by angiotensin II (Ang II) (106) and proinflammatory cytokines such as interferon gamma (IFN $\gamma)(201)$. Recent reports indicate the NOX5 isoform may also influence tubular physiology and contribute to glomerulopathies (112).

\section{Mitochondrial ROS}

Mitochondria in renal cells normally produce low levels of ROS, which are thought to play a role in cell signaling processes such as sensing hypoxia. However, the production of superoxide in the mitochondria is markedly enhanced by a variety of pathophysiological stimuli, including Ang II, tumor necrosis factor alpha (TNF $\alpha$ ), integrin ligation, diabetes and high glucose, oxidized LDL, and superoxide generated by NADPH oxidase $(27,298)$. These stimuli increase mitochondrial superoxide generation by affecting intracellular regulatory systems that increase intracellular calcium, open mitochondrial $\mathrm{K}_{\mathrm{ATP}}$ channels, and increase membrane potential. As a result, superoxide production occurs in complex I and complex III of the mitochondrial electron transport chain. In addition, hydrogen peroxide and lipid oxidation products can also enhance mitochondrial ROS generation in renal cells. A few well-understood mechanisms of mitochondrial ROS generation include the consequences of disruption of Fe-S clusters, inhibitory interactions with cytochrome c (cytc) oxidase, and relative changes in expression of electron transport chain components. It was also demonstrated that endothelial cells contain a mitochondrial NOS isoform that is capable of generating superoxide during stress (27).

Superoxide levels are normally kept at low levels in the mitochondrial matrix due to its conversion to hydrogen peroxide by mitochondrial matrix Mn-SOD (SOD2). The 
conversion of superoxide to hydrogen peroxide and its secretion from mitochondria appears to be important in renal signaling processes. However, it is critical for excessive mitochondrial superoxide to be detoxified to prevent damage to the mitochondria. If superoxide is not detoxified, it causes mitochondrial oxidative stress by disrupting iron-sulfur centers, releasing iron, and promoting processes that impair mitochondrial function. If superoxide and ROS generation is excessive in the mitochondria, mitochondrial membrane channels (including anion channels in the inner membrane) open (158), resulting in collapse of the mitochondria membrane potential and further generation of ROS by the electron transport chain (315).

Oxidative stress is worsened by reduced SOD2 levels. For instance, in CKD patients, SOD2 is downregulated in neutrophils during stress, causing their enhanced generation of ROS owing to the neutrophil dysfunction these patients have (214). In animal studies, ablation of SOD2 in mice results in accelerated renal cellular senescence and enhanced tubular damage, glomerular sclerosis, and renal interstitial inflammation upon aging (257). As superoxide and ROS generation in the mitochondria continues, it induces accumulation of uncoupling protein-2 (UCP2) (253). Increased UCP2 leads to the inward proton leak that interferes with the function of ATP synthase and reduces ATP synthesis (206), an effect that would impair ATP-dependent reabsorption processes in renal tubular epithelial cells. If these effects are severe enough, autophagy, apoptosis, or necrosis of these cells will occur (241).

Leakage of electrons from complex of I and II has been shown to mediate ROS-induced autophagy (40) and apoptosis. As ROS increases, oxidation of the acyl chains of cardiolipin reduces its binding affinity for cyt-c and liberates it from the inner mitochondrial membrane. Oxidized cardiolipin, along with permeabilization of the mitochondrial outer membrane by proapoptotic proteins of the B-cell lymphoma-2 (Bcl-2) family, causes release of cyt-c from the mitochondrial membrane into the cytosol, followed by formation of apoptosome, caspase activation, and consequently apoptosis (222).

\section{Oxidative Stress in the Renal Vasculature and Glomerulus}

\section{Renal vasculature}

The effects of ROS and RNS within the kidney during disease and/or injury appear to be spatially and temporally coordinated with potential multiple factors. All the cells associated with the renal vasculature, including endothelial cells, VSMCs, adventitial fibroblast, and both resident and infiltrating inflammatory cells, appear to be able to produce levels of ROS and/or RNS that promote pathophysiology. While ROS generation and signaling influence reabsorption of $\mathrm{Na}^{+}$in tubular cells throughout the nephron, it has direct effects on vasoreactivity in renal vessels with increased ROS associated with enhanced renal vascular resistance (RVR) (317). For instance, superoxide, primarily generated by NADPH oxidase in VSMCs, causes vasoconstriction and enhances basal tone in the medullary circulation of mice (340). Vascular oxidative stress plays a critical role in progression of kidney damage during disease. The endothelium is particularly vulnerable to oxidative stress and undergoes a change in phenotype as ROS levels in and around the blood vessels become moderate to severe. This adverse effect on the endothelium promotes inflammation, including enhanced cytokine production and expression of surface adhesion molecules (160) effectively promoting vascular remodeling.

Nitric oxide also plays a critical role in the endothelium during renal disease and oxidative stress. Low levels of nitric oxide (generated by endothelial nitric oxide synthase [eNOS]) induce expression of antioxidative genes, protect renal endothelial and mesangial cells from apoptosis and fibrosis (15, $62,144,237,270,313)$, and promote normal renal hemodynamics. In endothelial cells, in addition to being tethered to the cell membrane, eNOS can also present on the cytosolic face of the outer mitochondrial membrane (84). Physiological concentrations of nitric oxide in cells inhibit cyt-c oxidase (28), potentially altering mitochondrial ROS generation.

Moderately increased mitochondria ROS results in stabilization of hypoxia-inducible factor (HIF) in endothelial cells (99) and in stimulating nuclear factor E2-related factor (NRF-2) (235), effects that are both protective against oxidative stress and renoprotective $(107,196)$. The transcription factor NRF-2 is usually deactivated in an inhibitory complex with Kelch-like ECH-associated protein-1 (Keap-1). Once oxidative stress increases and Keap-1 is oxidized, NRF-2 is released and binds to the promotor region of nuclear respiratory factor-1 (NRF-1). NRF-2 binding promotes expression of numerous antioxidative molecules, including various enzymes of the glutathione and thioredoxin systems, SOD, catalase, HO-1, and other antioxidant molecules. In addition, ROS-induced stimulation of NRF-1 promotes activation of mitochondrial transcription factor A (Tfam) and stimulation of mitochondrial DNA replication/transcription and biogenesis $(93,326)$, effects aimed at preventing tissue damage. Reduced activity of NRF-2 has been implicated in the progression of renal failure in a mouse model of CKD (147).

During hypertension and $\mathrm{CKD}$, there is enhanced production of ROS in the kidney due to elevated NADPH oxidase activity, enhanced mitochondria respiration, and decreased efficiency in oxygen usage for $\mathrm{Na}^{+}$transport $(8,317)$. The increased level of ROS diminishes functional endotheliumderived nitric oxide by impairing and/or uncoupling NOS enzymes. This reduction in endothelial-derived nitric oxide is paramount in the progression of renal hemodynamic pathogenesis due to the loss ability of nitric oxide to induce vasodilation and counterbalance vasoconstrictors such Ang II, endothelin-1 (ET-1), and sympathetic nervous system outflow. As nitric oxide bioavailability continues to decrease, due to its reaction with superoxide and subsequent formation of peroxynitrite, RVR increases and nitric oxide-mediated pressure natriuresis is attenuated $(306,319)$. If the reduction in nitric oxide persists, endothelial dysfunction ensues and is potentially followed by the development of cardiovascular and renal diseases $(71,101,104,133)$.

\section{Glomeruli}

During the initial period of inflammation, the glomerular mesangium reacts by generating superoxide and hydrogen peroxide, mainly by NADPH oxidase (230). During certain disease states when there are elevated circulating levels of glucose, Ang II, and aldosterone (280), these factors further induce generation of ROS in mesangial cells $(156,262)$. In the case of Ang II and aldosterone, NADPH oxidase (NOX1) 


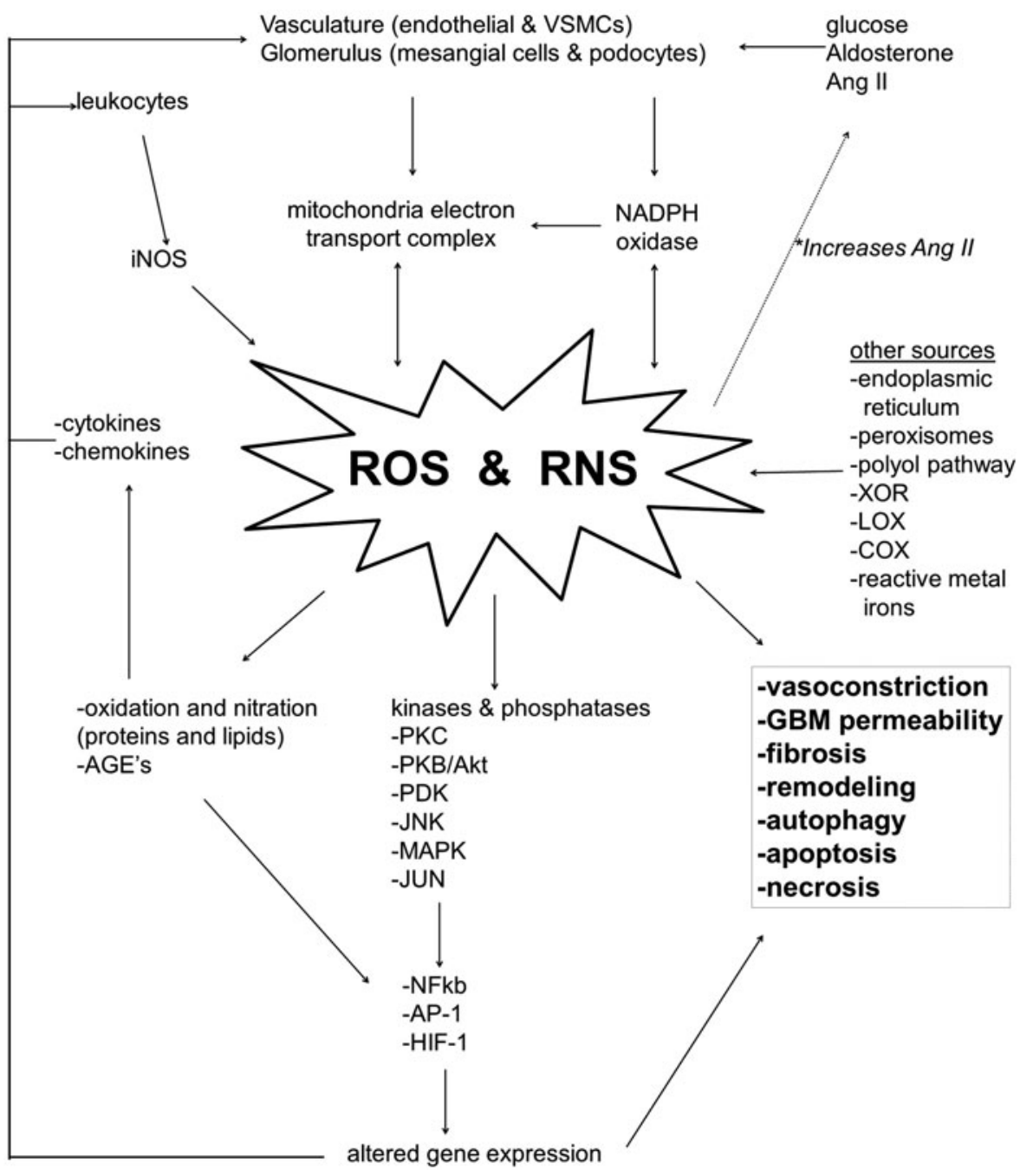

FIG. 1. The illustration of the signaling cascade and subsequent effects that ROS and RNS promote in cells of the renal corpuscle, including podocytes, endothelial, and mesangial cells. *Increased ROS and RNS increase Ang II, creating a positive feedback loop. RNS, reactive nitrogen species; ROS, reactive oxygen species; VSMCs, vascular smooth muscle cells. activity and superoxide production are induced via stimulation of the angiotensin II type 1 (AT1) receptor and mineralocorticoid receptors, respectively (121). The increased levels of ROS induce glomerular podocytes and mesangial cells to generate Ang II and reinforce feedback that promotes further ROS generation $(19,165,328)$.

As ROS generation endures, mitochondrial oxidative stress heightens $(19,165,328)$ and various kinase pathways are stimulated in mesangial cells, including protein kinase $\mathrm{C}$ (PKC) (154), protein kinase B (PKB)/Akt (97), PDK-1 (20), and c-Jun N-terminus kinase (JNK) (60). The stimulated kinase activity alters gene expression in mesangial cells. The perpetuating generation of ROS and resulting signaling pathways induces ROS modification of podocyte and glomerular proteins, as demonstrated in patients with CKD (48). A recent report demonstrated that the ROS can also directly influence the permeability of the glomerular basement membrane and alter glomerular filtration (292). If ROS generation continues to worsen, oxidative stress promotes autophagy and apoptosis in podocytes $(59,134,251)$ and mesangial cells $(24,189)$, promotion of profibrotic pathways and glomerulosclerosis, and interruption of the glomerular filtration barrier leading to proteinuria (292). The effects of ROS and RNS on cells of the renal glomerulus are illustrated in Figure 1.

\section{Infiltrating leukocytes}

As inflammation proceeds in the murine kidney, stressed mesangial and endothelial cells help recruit leukocytes to the glomerulus and perivascular regions by releasing ROS and proinflammatory cyto-/chemokines, including monocyte chemoattractant protein 1 (MCP-1), monocyte colonystimulating factor 1 (CSF-1), RANTES (regulated upon activation, normal $\mathrm{T}$ cell expressed and secreted), and intracellular adhesion molecule-1 (ICAM) (269). Consequently, leukocytes infiltrate the kidney and contribute significantly to the prodamage oxidative milieu. Despite the contribution of ROS by endothelial and mesangial cells, the main source of oxidative and nitrosative stresses in the glomerulus and perivasculature during kidney injury, such as that associated with sepsis, is derived from invading immune cells. Infiltrating leukocytes (including neutrophils and macrophages) invade the glomerulus and perivascular segments, release large amounts of proinflammatory cytokines such as interleukin-1beta (IL-1 $\beta$ ) and $\mathrm{TNF} \alpha$, and undergo a respiratory burst, which includes myeloperoxidase-enhanced release of superoxide (primarily by NADPH oxidase), hydroxyl radical-like species, hypochlorous acid, hydrogen peroxide, nitric oxide (via inducible nitric oxide synthase [iNOS]), and nitrogen dioxide $(260,329)$. The myeloid cells and 
macrophages that enter the kidney from the circulation also release proinflammatory cytokines due to induced ROSdependent activation of inflammasomes $(6,51)$.

The expression of iNOS is upregulated in rat mesangial cells during stress by various cytokines (including IL- $1 \beta$ and IFN $\gamma)(64,65,202,327)$, endotoxins (LPS), basic fibroblast growth factor (152), and by generators of ROS, including the hypoxanthine/xanthine oxidase (XO) system (14). High levels of iNOS-generated nitric oxide mediate proinflammatory effects by activating nuclear factor kappa-lightchain-enhancer of activated $\mathrm{B}$ cells $(\mathrm{NFkB})$ and activator protein-1 (AP-1) regulated transcription and further promoting production of iNOS and macrophage inflammatory protein-2 (MIP-2) (191, 313). The activity of iNOS continues to elevate RNS-induced toxic events in the kidney by nitrating proteins and lipids (231), an effect that further progresses renal damage in the rat $(94,96,207,208,228,304)$.

Controversy currently exists regarding the role of iNOSgenerated nitric oxide in the glomerulus. Various laboratories using murine models have reported that nitric oxide and RNS participate in apoptotic and necrotic death in mesangial cells $(24,118,189,192,265)$, resulting in loss of mesangial cells, matrix accumulation, and progression of glomerulonephritis $(197,316)$. In contrast, other reports have indicated that peroxynitrite and nitrosative stresses exert only minimal toxic effects on mesangial cells due to potential intrinsic defense mechanisms against RNS in these cells (265) and that inhibition of iNOS instead causes enhanced fibronectin deposition, hypercellularity, and proteinuria $(268,318)$. The discrepancy of the effects of nitric oxide appears to be related to its concentration. For instance, nitric oxide mediates renoprotective effects at a specific concentration range when its levels are low, but as iNOS-induced production of nitric oxide increases to pathological concentrations, its protective effects are lost and damage ensues. In comparison, vascular endothelial cells have demonstrated particular susceptibility to the toxic effects of peroxynitrite. Unlike their mesangial counterparts, endothelial cells in the glomerulus and perivascular structures do not appear to have a comparable protective system against nitrosative stress (230). Despite the conflicting reports, it appears, the generation of nitric oxide and ROS continues to play a part in their feedback loop effectively enhancing the generation and release of superoxide and hydrogen peroxide in leukocytes and glomerular mesangial cells. As tissue injury and inflammation progress, circulating and local tissue levels of cytokines such as IL- $1 \beta$ and TNF $\alpha$ (245) continue to increase, NADPH oxidase in renal cells is further stimulated, and ROS production becomes even more pronounced. These processes effectively amplify proinflammatory processes and tissue damage, causing cytoskeletal and vascular remodeling, fibrosis (25), and potential kidney failure.

After prolonged oxidative stress, an eventual shift in the balance of nitric oxide produced compared with ROS and RNS occurs in the renal glomerulus. During the shift, ROS and RNS generation is replaced by nitric oxide-dominated production in mesangial cells (231). It is believed that the shift results from the nitric oxide and ROS-induced amplification of cytokine-induced iNOS expression and subsequent upregulated nitric oxide generation in mesangial cells (14, 191, 230). As a result, ROS generation by NADPH oxidase is repressed by the presence of high amounts of generated nitric oxide (237), which effectively controls expression of the
NOX1 homolog of NADPH oxidase via cyclic guanosine monophosphate (cGMP)-dependent mechanisms (237). Afterward, nitric oxide production eventually slows due to exhaustion of NOS cofactors and/or nitric oxide-mediated inhibition of iNOS (230).

\section{Other renal ROS sources and their targets}

There are various other sources of ROS in the kidney. The uncoupling of eNOS results in superoxide generation during pathological conditions, such as diabetes and inflammation, when the availability of biopterin is reduced due to its oxidation (50). The endoplasmic reticulum generates ROS as a by-product of protein folding and oxidation (173). Fatty acid breakdown by peroxisomes accounts for superoxide generation [reviewed by Vasko and Goligorsky (301)]. Defects in the polyol pathway produce ROS while reducing glutathione synthesis. The enzymes, XO, lipoxygenase (LOX), and cyclooxygenase (COX), also contribute to ROS generation in the kidney. It was demonstrated that COX-2 can enhance production of ROS and subsequently enhance apoptosis in cultured mesangial and proximal tubular cells (PTCs). In addition, COX-2 inhibition with nonsteroidal anti-inflammatories (NSAIDs) reduces $25 \%$ of total kidney ROS production in the rodent kidney (146).

Other contributors to oxidative stress in the kidney include metal ions such as $\mathrm{Fe}^{3+}$ and $\mathrm{Cu}^{2+}$. In a rat model of cisplatin nephrotoxicity, iron release was blamed for renal damage due to its redox activity. Redox-active iron catalyzes (via the Haber-Weiss reaction) oxidative damage to proteins and lipids (lipid peroxidation), events that are strongly associated with renal disease and its severity (187). In fact, the level of lipid peroxidation in the kidney is typically used as a marker for severity of kidney damage and can assist physicians in screening kidneys that are suitable for transplant. Increased lipid peroxidation and the subsequent formation and renal accumulation of advanced lipoxidation end products trigger proinflammatory pathways that include activation of the receptor for advanced glycation end products (125).

Amino acids that contain sulfhydryl groups, such as cysteine and methionine, are the major targets of oxidation due to the susceptibility of their thiol groups to become oxidized. The sulfhydryl groups in these amino acids can easily be oxidized by hypochlorous acid, peroxides, and peroxynitrite (187). Tyrosine, tryptophan, arginine, proline, lysine, and histidine are also susceptible to oxidation (168), while lysine is particularly susceptible to modification due to lipid peroxidation (103). The post-translational oxidative modification of proteins at these amino acids can alter the protein's function. For instance, the prodamage alarmin HMGB1 is rapidly released into the circulation from renal endothelial and epithelial cells after injury, as demonstrated in numerous rodent studies $(38,46,159,166,242,324)$. Three key cysteine motifs in HMGB1 dictate the protein's function. If these cysteine residues are reduced thiols, then circulating HMGB1 induces repair of the injured tissues $(272,310)$. However, as these cysteine residues become oxidized to disulfide bonds, the reparative effects of the protein are lost and instead HMGB1 promotes inflammation and damage (307, 330). Other examples include the regulation of kinases, phosphatases, and even histone deacetylases (HDAC) (246). The immediate cellular redox microenvironment dictates the thiol-disulfide redox state of cysteine residues within these 
enzymes, an effect that subsequently either activates or inhibits the enzyme's activity.

In addition to protein modification, ROS and RNS can oxidize carbohydrates (producing advanced glycated end products [AGEs]) and damage DNA. A strong correlation exists in human patients with severity of kidney disease and elevated levels of AGEs (16, 172, 185, 188, 226, 305). Circulating and cellular AGEs induce lipid peroxidation products in the kidney and/or bind to receptors, activate intracellular signaling pathways, including $\mathrm{NFkB}$, and subsequently activate cytokine and ROS production $(227,273)$. These proinflammatory effects are worsened as AGE suppresses intracellular antioxidant systems, including the glutathione system, an effect which further promotes renal damage.

\section{ROS-induced gene expression and fibrosis}

The effects of ROS and RNS also induce kidney damage by influencing gene expression at the transcriptional level and altering protein function via post-translational modifications $(13,23,232,233,276)$. Altered gene expression results from the induction of several redox-sensitive transcription factors (including NFkB, AP-1, and HIF-1) and the oxidation, nitration, and nitrosation of the potential 500 kinases and 200 phosphatases contained in the cells of the human kidney (23, $91,176,181,233,234)$. Oxidative stress downregulates protein tyrosine phosphatases, while upregulating protein tyrosine kinases, including JNK and p42/p44 (ERK-1/ERK-2) mitogen-activated protein kinase (MAPK) pathways $(23,123,130$, 151,290), although nitric oxide-induced activation of soluble guanylate cyclase and generation of cGMP triggers phosphorylation events that may counteract some of these effects.

High-glucose levels, as occurs during diabetic nephropathy, lead to increased ROS in mesangial cells via activation of PKC (ROS can also directly enhance PKC activity constituting a positive feedback loop) (100). ROS-stimulated PKC signaling then subsequently activates MAP kinases in mesangial and endothelial cells, followed by activation of the transcription factors, NFkB and AP-1, altered expression of MCP-1 and metalloprotease $9(63,89,230)$, and stimulation of the proinflammatory effects of heat shock proteins (HSPs) (238) and osteopontin (97).

ROS upregulation of transforming growth factor beta (TGF- $\beta$ ) in mesangial and endothelial cells stimulates SMAD signaling and subsequently enhances expression of collagen 1,3 , and 4, fibronectin, and plasminogen activator inhibitor1 , while attenuating activity of extracellular matrix (ECM) degradation factors $(11,126,221,230)$. It is well documented that activation of these signaling pathways leads to enhanced mesangial cell proliferation and hypercellularity, increased mesangial matrix formation, and renal fibrosis in mammals. Glomerulosclerosis also results from ROS generated as a result of aldosterone and Ang II signaling, which activates p38 MAPK and promotes smooth muscle and mesangial cell proliferation, production of fibronectin and collagen, and subsequent fibrotic expansion of the $\operatorname{ECM}(78,97,165,184)$.

\section{Oxidative Stress in the Renal Tubules}

\section{Proximal tubule}

Within the nephron, the proximal tubule is a major site of ROS generation due to its immense production of ATP by oxygen consumption to support the massive active transport that takes place in these epithelial cells. The PTC requires ATP for critical $\mathrm{Na}^{+} / \mathrm{K}^{+}$ATPase, which maintains the intracellular-extracellular electrochemical gradient that drives the transport processes of several factors (175). The PTCs produce the required ATP by highly oxidative glucose metabolism, which renders these cells sensitive to oxidative stress due to a highly active mitochondrial electron transport chain. To make matters worse, studies on rats have indicated that unlike other segments of the nephron, proximal tubules cannot synthesize glutathione, but instead depend on circulating glutathione for antioxidant protection against mitochondrial-generated ROS (311). The enhanced vulnerability of PTCs to oxidative damage plays a central role in the renal pathogenesis of conditions such as diabetes.

During diabetes and hyperglycemia, excessive glucose is filtered and reabsorbed by PTCs by sodium-dependent glucose transporters (175). The excessive availability of glucose enhances glycolysis, which leads to a high mitochondrial proton gradient in PTCs, resulting in the elevated production and release of mitochondrial superoxide and ROS (203). Increased glucose uptake also stimulates PKC-dependent activation of NADPH oxidase (which is highly expressed in PTCs, particularly NOX4), resulting in excessive production of superoxide by NADPH oxidase $(21,262)$. In addition to high glucose, elevated levels of Ang II (acting on the AT1 receptor) also cause a rise in NADPH oxidase-derived superoxide generation in PTCs (primarily by NOX4) (224).

Enhanced generation of superoxide and ROS reduces $\mathrm{Na}^{+}$ reabsorption in the proximal tubule of rats by increasing the expression of the $\mathrm{Na}^{+} / \mathrm{H}^{+}$exchanger regulatory factor (NHERF2), which inhibits $\mathrm{Na}^{+} / \mathrm{H}^{+}$exchanger (NHE3) activity (224). Nitric oxide typically enhances $\mathrm{Na}^{+}$and fluid reabsorption in the proximal tubule, thus the observed reduction of $\mathrm{Na}^{+}$reabsorption that occurs in the proximal tubule appears to also be a result of reduced availability of nitric oxide, possibly due to NOS uncoupling and/or nitric oxide reaction with increased superoxide. Thus, various signaling factors converge synergistically on the proximal tubule to blunt $\mathrm{Na}^{+}$reabsorption. However, $\mathrm{Na}^{+}$reabsorption is compensated for in other segments of the nephron downstream from the proximal tubule as superoxide enhances $\mathrm{Na}^{+}$reabsorption in the medullary thick ascending limb (mTAL) and distal nephron, in contrast to the effects of ROS in the proximal tubule (224).

In addition to diabetic nephropathy, the proximal tubule is severely damaged during various toxin-induced nephropathies. For example, nephrotoxic substances, including antibiotics (e.g., gentamicin), antivirals (e.g., tenofovir), immunoglobins, radio-contrast media, heavy metals (e.g., cadium), and chemotherapy reagents such as cisplatin (293), directly injure the proximal tubule. Many of these toxins induce ROS and RNS in the proximal tubule $(43,297)$ and inhibit the mitochondrial electron transport chain, prompting mitochondrial damage and consequently disrupt tubular function. Heavy metals can react with antioxidants and/or their cofactors and effectively inhibit their activity. Heavy metals have been shown to deplete antioxidant systems, including the glutathione and thioredoxin systems, thus allowing for accumulation of ROS. Through the Fenton reaction, metals can also induce the formation of highly reactive prodamage hydroxyllike radicals. As a result, the enhanced oxidative stress causes DNA damage, protein oxidation, and lipid peroxidation, 
factors that lead to cell dysfunction and/or cell death by either apoptosis or necrosis (293).

The effects of oxidative stress on apoptosis have been closely examined; however, the mechanisms by which oxidative stress induces necrosis are not yet completely understood. As oxidative stress becomes more severe and prolonged in the kidney, cells undergo necrosis along with apoptosis (Fig. 2). The specific redox signaling that determines if a cell will undergo apoptosis or necrosis is still not clearly defined. However, it is known that ROS and RNS promote apoptosis by directly activating caspase 3 and 8 (via cysteine oxidization) (26) and inducing death receptor clustering on the plasma membrane $(70,261)$. As the mitochondrial permeability transition complex fails, there is outer membrane permeabilization and cyt-c translocation. These events trigger caspase signaling, apoptosome formation, and apoptosis $(70,261)$. As oxidative stress continues, there is mitochondrial swelling, dysfunction, and failed ATP production, events that promote necrosis (44). ROS activation of JNK results in stimulation of both the proapoptotic apoptosis

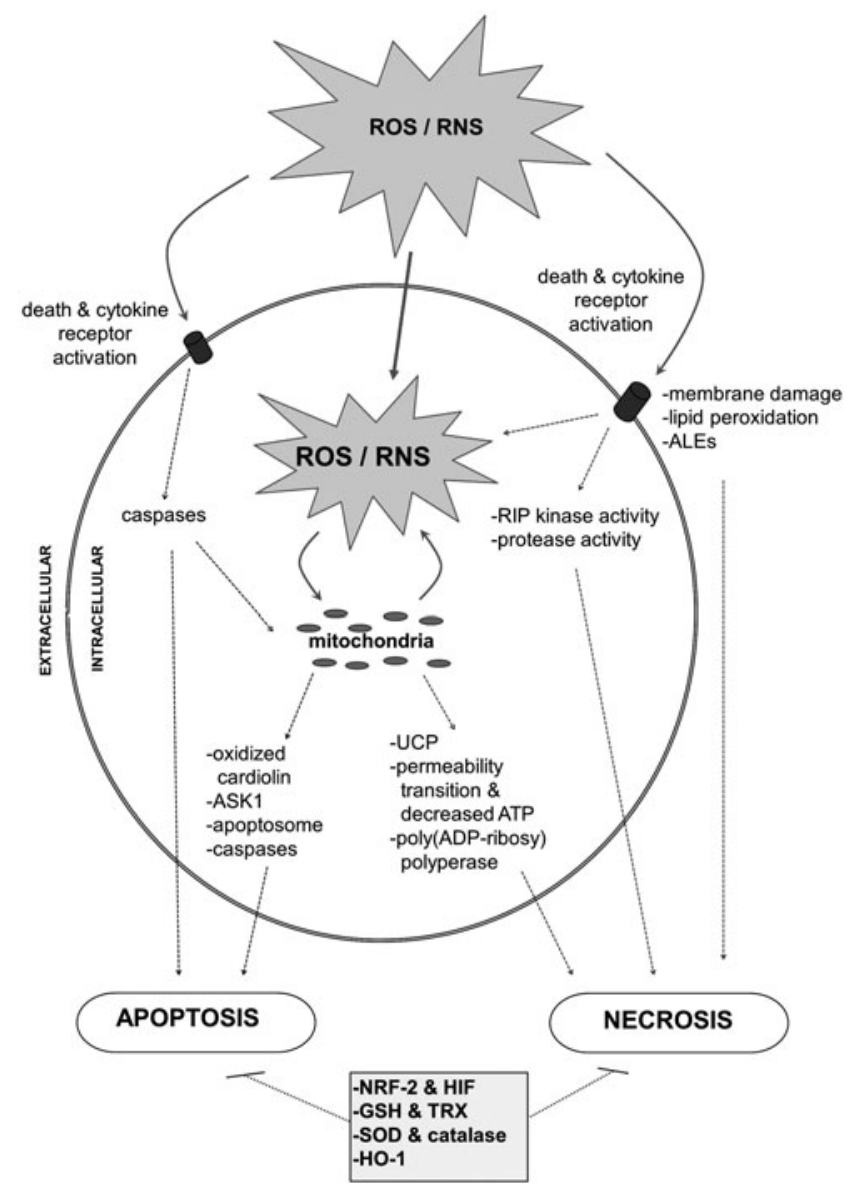

FIG. 2. Depiction of the determining events that occur in a renal cell during oxidative stress that determine if the cell will undergo apoptosis or necrosis. Mild ROS and RNS stress induces apoptosis. As oxidative stress continues, cell and mitochondrial membranes are damaged and necrosis ensues. Various endogenous antioxidant systems can prevent apoptosis and necrosis by attenuating oxidative stress, including factors upregulated by NRF-2. NRF-2, nuclear factor E2-related factor. signaling kinase 1 (ASK1) (via JNK) $(57,164)$ and the necrotic death promoter poly(ADP-ribosyl) polyperase (PARP1) (44). Necrosis also results from the enhanced release of proinflammatory factors, increased lipid peroxidation, and loss of membrane integrity, all factors directly induced by ROS and/or RNS $(105,162)$.

Similar to mesangial cells in glomeruli, ROS in PTCs stimulate the PKB/Akt, MAP, and Janus kinase phosphorylation cascade, which stimulates the activation of various transcription factors (including NFkB, AP-1, SP-1, and STAT) and upregulates expression of TGF- $\beta$ (120). As discussed previously, the cytokine, TGF- $\beta$, plays a critical role in the development of renal fibrosis in many pathological states. Signaling of TGF- $\beta$ via the SMAD pathway induces endothelial- and epithelial-mesenchymal transition, in which differentiated kidney cells lose their functional phenotype and instead become myofibroblasts. Once these cells transition into myofibroblasts, they begin producing excessive extracellular matrix proteins, including various collagens leading to tubulointerstitial fibrosis and impairment of kidney function $(289,338)$. Ultimately, the severity of tubulointerstitial fibrosis is closely related to both TGF- $\beta$ levels and the progression of kidney disease (67).

\section{Genetic tubular diseases}

Oxidative stress in the proximal tubule also plays a role in the progression of human genetic renal diseases. For example, enhanced ROS formation has been linked to cystinosis and development of the proximal tubular disease Fanconi syndrome (81). More specifically, cystinosis is a disease that results in renal proximal tubular dysfunction and defective transport of cystine across the lysosomal membrane (293). The accumulation of intracellular cystine induces oxidative stress and reduces mitochondrial ATP generation, leading to PTC damage and apoptosis (248). The loss of renal PTCs leads to Fanconi syndrome, decreased activity of $\mathrm{Na}^{+} / \mathrm{K}^{+}$ ATPase activity in the proximal tubule, and ensuing attenuation of tubular transport of glucose, amino acids, electrolytes, and water $(18,76)$. Dent's disease, which is an X-linked recessive inherited condition and another cause of Fanconi syndrome, has also recently been suggested to be caused, in part, by enhanced oxidative stress (97).

\section{Medulla}

As the proximal tubule dives deeper into the cortex and into the medullary region of the kidney, levels of hydrogen peroxide are exacerbated by twofold, as was demonstrated in a rat model (42). The enhancement of hydrogen peroxide in the renal medulla is further exaggerated during hypertension (42) and proteinuria. In the case of proteinuria, proteins that leak into the filtrate consequently activate glia maturation factor- $\beta(\mathrm{GMF}-\beta)$ in the proximal tubule (140). Activated GMF- $\beta$ increases the generation of hydrogen peroxide in and around the proximal tubules by upregulating hydrogen peroxide-producing enzymes (CuZn-SOD) and concomitantly attenuating hydrogen peroxide-reducing enzymes (glutathione peroxidase, glutathione, and catalase) $(140,293)$.

Depending on the vascular bed, hydrogen peroxide can elicit vasodilation, vasoconstriction, or a biphasic effect (41, $52,85)$. In the rodent kidney, hydrogen peroxide reduces blood flow in the renal medulla and enhances contraction of 
the afferent arteriole to Ang II and ET-1 (250). These effects by hydrogen peroxide alter renal autoregulatory mechanisms by enhancing the myogenic and macula densa tubuloglomerular feedback responses, modify the expression and release of renin by juxtaglomerular cells $(82,83,131,250)$, and subsequently reduce sodium excretion (in contrast to the increased $\mathrm{Na}^{+}$excretion that occurs in response to elevated ROS in the cortical proximal tubule) (247). The hydrogen peroxide-induced sodium retention results in salt-sensitive augmentations to blood pressure in the rat (321). This is further compounded by the ability of ROS to impair dopamine receptors in the tubules and decrease natriuresis $(10$, $288,335)$. Furthermore, hydrogen peroxide directly affects apoptosis and cell survival by inducing $A s k l$ and activation of phospholipase A2 and the p38 MAPK pathway in PTCs (3, $53,95,194)$. These affects at least contribute, if not mediate, hydrogen peroxide promotion of cardiovascular and renal dysfunction $(42,286,287)$.

\section{Albumin}

Serum albumin has been examined for its role in contributing or preventing oxidative stress in the proximal tubules. It appears that albumin has antioxidant capabilities at lower concentrations, but in contrast, it induces generation of ROS at higher levels. Albumin is the major protein constituent in plasma and undergoes small-scale filtration in the glomerulus. At physiological low concentrations, albumin protects renal PTCs by activating PKB, which leads to phosphorylation of the Bad protein and inhibition of apoptosis $(31,293)$. At low concentrations, albumin also effectively functions as an antioxidant by scavenging ROS and preventing formation of hydroxyl radical-like species via the Fenton reaction due to its binding to highly oxidative transition metals such $\mathrm{Fe}^{3+}$ and $\mathrm{Cu}^{2+}(102,293)$. In addition to scavenging oxidants extracellularly, filtered albumin also protects PTCs upon endocytosis. For example, studies have shown that when albumin uptake by the PTC is reduced, the antioxidative effect of albumin is removed and subsequent oxidative stress ensues, followed by renal disease progression and tubulointerstitial fibrosis $(81,167,254)$.

In contrast, at high concentrations, albumin promotes deleterious effects. During periods of glomeruli injury or damage to the glomerular filtration barrier, which results in augmented protein load in the tubular filtrate, there is excessive albumin endocytosis by PTCs. The high albumin load within PTCs activates PKC activity, followed by activation of (NOX4) NADPH oxidase and generation of superoxide. High levels of albumin also enhance its binding to fatty acids, which effectively impairs SOD2 activity in PTCs while promoting mitochondrial ROS production (128). The increase in ROS in the cytosol of PTCs activates STAT, NFkB, and AP-1 intracellular signaling cascades, leading to expression of proinflammatory genes and promotion of interstitial fibrosis in the kidney (293).

\section{Medullary thick ascending limb}

Continuing through the nephron, a large fraction of $\mathrm{Na}^{+}$is reabsorbed from the filtrate in the mTAL (also referred to as the distal straight tubule), particularly when proximal tubule reabsorption is reduced. The apical $\mathrm{Na}^{+} / \mathrm{K}^{+} / 2 \mathrm{Cl}^{-}$cotransporter (NKCC) accounts for the bulk of $\mathrm{Na}^{+}$reabsorp- tion in this portion of the nephron (upward of $80 \%$ ), with NHE3 handling the rest of $\mathrm{Na}^{+}$reabsorption in this segment (8). During various episodes of renal stress and/or disease, this region of the nephron is subject to the adverse effects of oxidative stress.

In the mTAL, various sources contribute to the generation of superoxide, including XO-reductase, COX, and CYP450 enzymes, although the major producer of superoxide in this segment is NADPH oxidase $(8,88)$. NADPH oxidase is also the main source of superoxide generation in the mTAL in response to Ang II and increased luminal flow (8, 114, 274, 284). Superoxide generated in the mTAL of the rat kidney activates the PKA signaling pathway and stimulates $\mathrm{Na}^{+} / \mathrm{K}^{+}$ ATPase and NKCC activity, which subsequently enhances $\mathrm{Na}^{+}$transport and reabsorption $(218,284)$. However, in contrast to its action in the proximal tubule, nitric oxide inhibits NKCC and NHE3 in the mTAL, thus effectively reducing $\mathrm{Na}^{+}$reabsorption and potentially counteracting the superoxide-induced enhancement of $\mathrm{Na}^{+}$reabsorption (87, $219,220)$. It is expected then that since $\mathrm{Na}^{+}$reabsorption in the mTAL is enhanced during periods of oxidative stress, nitric oxide availability is decreased, possibly due to NOS uncoupling or nitric oxide reaction with ROS to form RNS $(86,87)$. It also appears that the arachidonic acid metabolite, 20-hydroxyeicosatetraenoic acid (20-HETE), plays a role in ROS-dependent enhanced $\mathrm{Na}^{+}$reabsorption in the mTAL. Increased ROS causes 20-HETE levels to decline, which in turn enhances mTAL Na${ }^{+}$reabsorption in rodent models by unclear mechanisms $(110,320)$.

\section{Distal tubule and collecting duct}

In the distal tubule and collecting duct, the vast majority of $\mathrm{Na}^{+}$reabsorption occurs via the epithelial $\mathrm{Na}^{+}$channel $(\mathrm{ENaC})$. Ang II (acting on AT1 receptors) and aldosterone have been shown to increase ENaC activity in the collecting duct by NADPH oxidase-dependent generation of ROS (291, 336). High intake of $\mathrm{NaCl}$ has also been shown to increase $\mathrm{ENaC}$ activity by promoting hydrogen peroxide formation (291). Thus, ROS increases $\mathrm{Na}^{+}$reabsorption in the distal tubule and collecting duct by stimulating ENaC.

Despite the decrease in $\mathrm{Na}^{+}$reabsorption that occurs in the proximal tubule, oxidative stress overall results in sodium retention due to enhanced RVR, altered tubuloglomerular feedback, reduced GFR, and increased sodium transporter activity in the later portion of the nephron (Fig. 3).

\section{Therapeutic Antioxidant Treatment}

Despite reports that have demonstrated that oxidative stress plays a significant role in AKI and CKD along with cardiovascular disease, application of antioxidants clinically to patients with a variety of kidney injuries and diseases has been met with limited success. A major hurdle that poses a significant problem for any therapeutic treatment is the complexity of the multifaceted sources of oxidative stress and their dynamic interconnection. While resident renal cells, such as endothelial, mesangial, and tubular cells, generate ROS during stress, infiltrating leukocytes also produce damaging ROS and RNS as well. This makes cellular targeting of therapeutic antioxidants difficult due to the widespread nature of the cells involved in the process. This is further complexed by the generation of ROS and RNS in 
FIG. 3. A schematic of the effects ROS and RNS have on $\mathrm{Na}^{+}$ reabsorption throughout the renal nephron, including signaling effector molecules. While $\mathrm{Na}^{+}$reabsorption is reduced in the PT, overall, oxidative stress results in enhanced sodium reabsorption in the kidney due to upregulated $\mathrm{Na}^{+}$ reabsorption in the mTAL, DT, and $\mathrm{CD}$. Protein in the filtrate stimulates production of hydrogen peroxide in the tubule, especially in the medulla where hydrogen peroxide levels are alleviated. CD, collecting duct; DT, distal tubule; mTAL, medullary thick ascending limb; PT, proximal tubule.

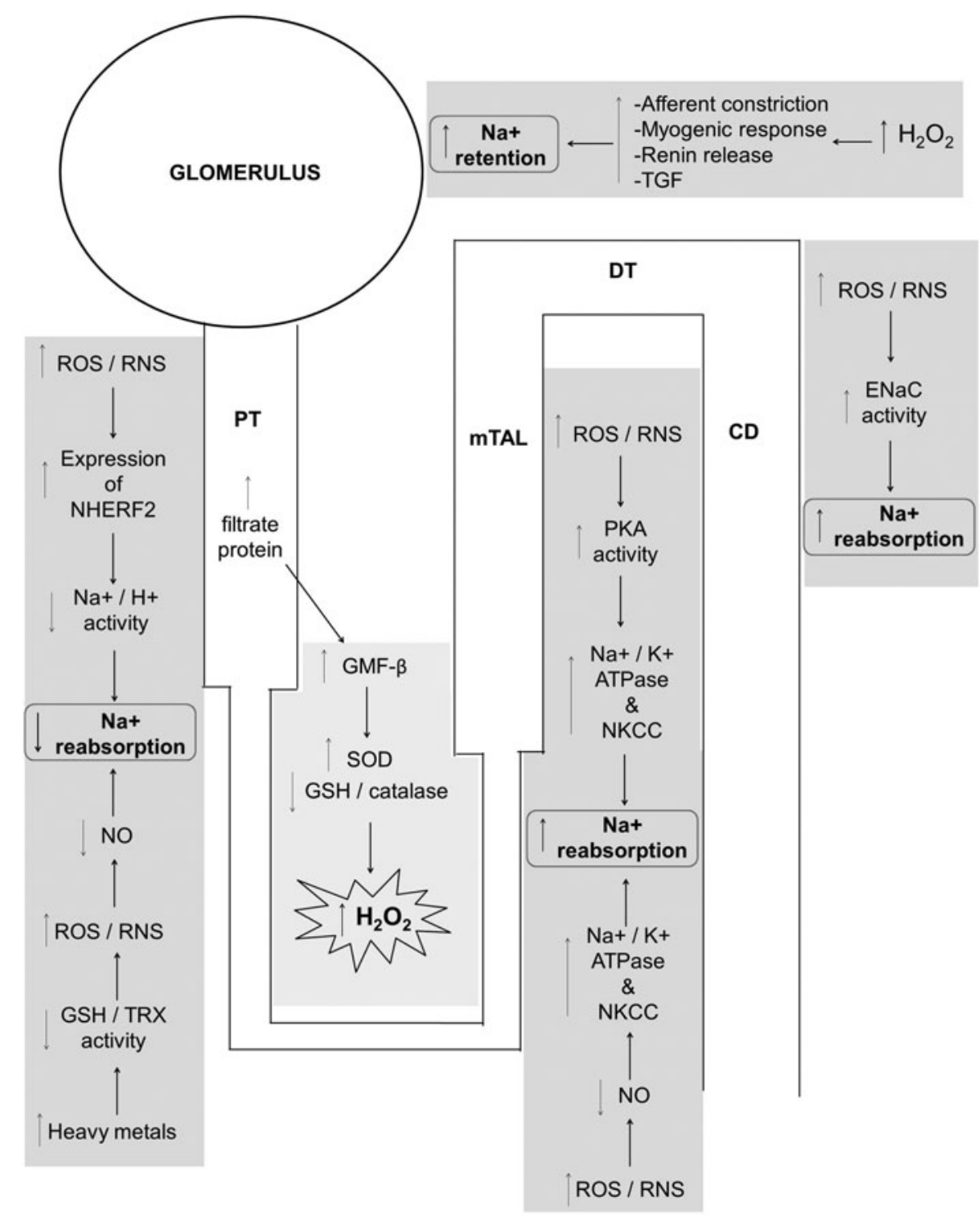

multiple compartments within the cell and in the extracellular environment. This means therapeutic treatments must specifically target both the source of oxidative stress and its specific cellular location.

To make matters more complex, low-level ROS signaling is required to maintain normal physiological function and for preservation of cellular homeostasis. Thus, complete inhibition of oxidative stress generation would impair the normal function of the cells by suppression of prosurvival and reparative signaling. Such is the case in regard to hydrogen peroxide. Low levels of hydrogen peroxide play a role in maintaining basal tone in vascular beds throughout the body, including the kidneys, thus its removal would impair normal hemodynamic function. Another example is nitric oxide, which also maintains normal vasoreactivity in vascular beds in addition to suppressing cellular apoptosis and leukocyte adhesion in vessels.

Regardless of the hurdles associated with developing effective antioxidant therapeutic strategies, the administration of various antioxidants in in vitro experiments and in animal models of both acute and chronic kidney injuries has shown therapeutic potential. However, when the same antioxidant molecules are tested in humans, the potential is not realized, and in some cases, these antioxidants worsened patient renal impairment and outcome. The conflicting results may, in some regard, be due to administration of antioxidants at doses that are not optimal. Table 3 lists some of the current and significant antioxidants that are being examined for their renoprotective effects.

\section{$\mathrm{N}$-acetylcysteine}

While clinical trials to date have not been encouraging, there are a few antioxidant molecules that have demonstrated limited therapeutic efficacy in humans. The antioxidant compound that has undergone the most elaborate clinical testing is $\mathrm{N}$-acetylcysteine (NAC). NAC elicits its potential therapeutic effects by replenishing intracellular levels of glutathione and also by direct scavenging of free radicals. While NAC has been shown to reduce lipid peroxidation, maintain mitochondrial membrane potential, and prevent apoptosis in various animal models (rats, pigs, and canines) 
Table 3. The Benefits and Shortcomings of Various Antioxidants

\begin{tabular}{|c|c|c|}
\hline Antioxidant & Effect & Reference \\
\hline \multirow[t]{5}{*}{ NAC } & $\begin{array}{l}\text { Reduces lipid peroxidation and apoptosis in animal models and in } \\
\text { kidney cell cultures }\end{array}$ & $4,129,157,322$ \\
\hline & Reduces inflammatory cytokines in ESRD patients & 113,192 \\
\hline & Improves kidney function in kidney transplant patients & 51 \\
\hline & No change in serum creatinine or BUN in CKD patients & 180 \\
\hline & No improvement in proteinuria of kidney damage in CKD patients & 243 \\
\hline \multirow{2}{*}{ Edaravone } & Neuroprotective in stroke patients & 111 \\
\hline & $\begin{array}{l}\text { Prevents lipid peroxidation and protects kidney function during IRI- } \\
\text { induced AKI in animals }\end{array}$ & 58 \\
\hline Ebselen & $\begin{array}{l}\text { Reduces lipid peroxidation, kidney damage, and serum creatinine in } \\
\text { animal models of kidney injury }\end{array}$ & $37,55,144,215$ \\
\hline $\begin{array}{l}\text { CoQ10 (including } \\
\text { MitoQ) }\end{array}$ & $\begin{array}{l}\text { Improves glomerular and tubular damage, reduces fibrosis, and } \\
\text { improves kidney function in animal models of AKI }\end{array}$ & $33,55,121,144,215$ \\
\hline \multirow[t]{2}{*}{$\alpha$-Lipoic acid } & Is renoprotective during various kidney injuries in animals & $45,174,266,323$ \\
\hline & Preserves kidney function in diabetic patients & 302 \\
\hline \multirow{3}{*}{$\begin{array}{l}\text { Vitamin E (including } \\
\text { MitoV) and } \\
\text { vitamin C }\end{array}$} & $\begin{array}{l}\text { Improves kidney damage and function during IRI-induced AKI in } \\
\text { animals }\end{array}$ & 66,313 \\
\hline & Reduces the risk for CKD in humans & $22,89,123$ \\
\hline & $\begin{array}{l}\text { No beneficial effects during kidney injury in humans; increased } \\
\text { mortality in humans }\end{array}$ & 103,116 \\
\hline \multirow[t]{2}{*}{ Bardoxolone methyl } & $\begin{array}{l}\text { Enhanced NRF-2 activity, reduced oxidative stress, reduced kidney } \\
\text { damage, and improved kidney function in animal models of kidney } \\
\text { injury }\end{array}$ & $107,220,315$ \\
\hline & Failed clinical studies; increased mortality in humans & \\
\hline Curcumin & $\begin{array}{l}\text { Improves kidney function in animal models of kidney injury } \\
\text { Activates NRF-2 and HO-1 }\end{array}$ & $102,163,290$ \\
\hline Resveratrol & $\begin{array}{l}\text { Enhances NRF- } 2 \text { signaling, improves mitochondrial and kidney function } \\
\text { in animal models of kidney injury }\end{array}$ & $34,35,147,234,255$ \\
\hline Ethyl pyruvate & $\begin{array}{l}\text { Reduces oxidative stress, cyto-/chemokine release, inflammation, and } \\
\text { kidney damage in animals during AKI } \\
\text { Improves kidney function in animals during AKI }\end{array}$ & $44,151,177,233$ \\
\hline Calendula & $\begin{array}{l}\text { Improves kidney damage and function during cisplatin-induced } \\
\text { nephropathy in animals }\end{array}$ & 231,298 \\
\hline Sulforaphane & $\begin{array}{l}\text { Upregulates NRF-2 signaling and protects mitochondrial function } \\
\text { Protects kidney function and reduces kidney damage during AKI and } \\
\text { diabetic nephropathy in animals }\end{array}$ & $143,194,270$ \\
\hline $\begin{array}{l}\text { Ang II/AT1 Rec } \\
\text { inhibitors }\end{array}$ & $\begin{array}{l}\text { AT1 receptor blockers (losartan, telmisartan, irbesartan, and } \\
\text { candesartan) reduce oxidative stress in the kidneys during disease and } \\
\text { injury and improve kidney function and proteinuria } \\
\text { Variable adverse side effects }\end{array}$ & $9,139,204,258$ \\
\hline
\end{tabular}

AKI, acute kidney injury; Ang II, angiotensin II; AT1, angiotensin II type 1 receptor; CKD, chronic kidney disease; CoQ10, coenzyme Q10; ESRD, end-stage renal disease; NAC, N-acetylcysteine; NRF-2, nuclear factor E2-related factor.

$(4,135,163)$ and cultured human PTCs (332), its use for the treatment of patients with CKD has been disappointing (186, 252). However, in patients with end-stage renal disease, NAC did reduce inflammatory cytokines $(119,198)$ while improving early outcomes in kidney transplant recipients (54).

\section{Edaravone and ebselen}

A variety of antioxidants, including edaravone and ebselen, have demonstrated the ability to improve renal function in animal models of kidney injury/disease, but these effects remain to be validated in human studies. Edaravone is an antioxidant that reduces levels of ROS, including hydroxyl radical-like and peroxyl-free radicals (2, 204, 339). Ebselen has the ability to metabolize peroxides by utilizing glutathione or through direct reduction of thioredoxin reductase and thus has been referred to as a glutathione peroxidase mimetic. While edavarone has not been examined thoroughly in human patients with $\mathrm{AKI}$ or $\mathrm{CKD}$, it has been proven to be neuroprotective in stroke patients (117), while protecting renal function in a rat renal IRI model (61). The delivery of the seleno compound ebselen has demonstrated the benefits of scavenging nitrosative species. Ebselen is an antioxidant that scavenges peroxynitrite without effecting endogenous nitric oxide (195), making this antioxidant very attractive for treatment of oxidative stress-related pathological conditions. In various animal models of AKI, ebselen application prevented lipid peroxidation, enhanced endothelial and epithelial cell viability, and improved renal function $(35,39,58,94$, $150,207,223,228)$. However, the benefits of ebselen remain to be seen in human subjects.

\section{Mitochondrial antioxidants}

Various antioxidants that target and improve mitochondrial oxidative stress and function have been investigated. The molecule coenzyme Q10 (CoQ10), which is a component of cell membranes and plays a role in mitochondrial 
electron transfer and free radical quenching, has been shown to improve renal function in heminephrectomized rats (127). In humans, CoQ10 appears to prevent mitochondrial dysfunction, but more studies are still required to determine if CoQ10 is effective for treatment of CKD.

Other compounds that target the mitochondria have gained interest in recent years for treatment of kidney injury and disease, including mitoquinone mesylate (a derivative of CoQ10, termed MitoQ) and $\alpha$-tocopherol-conjugated triphenylphosphonium (otherwise referred to as MitoVit E or mitochondrial targeted vitamin E). Animal studies with MitoQ have shown its ability to improve renal function during diabetic nephropathy, toxin-induced nephropathy, and IRI-induced AKI $(34,58,150,223)$. However, it remains to be seen if MitoQ improves renal function in human CKD patients.

Another mitochondrial targeting agent, the dithiol $\alpha$-lipoic acid, is a cofactor for mitochondrial bioenergetic enzymes. $\alpha$ Lipoic acid has been shown to be renoprotective in numerous animal studies that utilized various kidney injury models (47, $180,275,333)$. $\alpha$-Lipoic acid preserves NOS function by preventing or reversing biopterin oxidation. The effects of $\alpha$ lipoic acid improve endothelial function in diabetic patients (312) and may prove to be effective in preserving renal function in these patients as well.

\section{Vitamin $E$}

Another approach to combat the oxidative stress associated with kidney injury and disease is to enhance endogenous antioxidative systems by dietary supplementation. Supplementation should contain various metal ion cofactors (such as manganese, chromium, and selenium) and/or vitamins A, C, and $\mathrm{E}$ to potentially induce antioxidant benefits. Vitamin $\mathrm{E}$ supplementation has received considerable attention for treatment of various oxidative pathological conditions. Vitamin $\mathrm{E}$ incorporates into the plasma membrane, scavenges free radicals, and prevents lipid peroxidation (277). After vitamin $E$ is oxidized due to scavenging of ROS (particularly peroxyl radicals), vitamin $\mathrm{C}$ reduces and effectively restores the antioxidant capabilities of vitamin E (79, 137, 138), followed by vitamin $\mathrm{C}$ restoration by glutathione and lipoic acid (98). Supplementation with vitamin E analogs has demonstrated beneficial effects for treatment of IRI-induced AKI in animals $(69,323)$. In humans, patients with CKD demonstrate reduced levels of vitamin E. However, clinical trials have reported both beneficial results upon introduction of vitamin $\mathrm{E}$ analogs, including reduced risk of CKD $(22,92$, 129), and, in contrast, an absence of any beneficial effects (109) and even enhancement of mortality (122).

\section{Naturally occurring antioxidants}

While medicinal plants have been used for generations for treatment of various diseases, their therapeutic potential has yet to be fully explored in the clinic. Natural medicines may prove to possess a wealth of effective antioxidant molecules and/or antioxidant-stimulating capabilities that can be used for effective treatment of kidney injury and disease. For instance, the substance calendula has been isolated from the marigold plant and has been successfully used for treatment of cisplatin-induced nephropathy in a rodent model (240, 308), but its therapeutic potential remains to be explored in humans. There are numerous other plants and naturally oc- curring compounds with antioxidant properties, including carotenoids and phenolic compounds. Flavonoids (such as quercetin, soy isoflavones, and silibinin) represent one group of naturally occurring phenolic compounds that have been studied for their antioxidant capabilities, cardiovascular protection, and anti-inflammatory properties (72). While foods rich in flavonoids are recommended for patients with $\mathrm{CKD}$, it remains to be seen if pharmacological flavonoid treatment offers advantages for patients with CKD.

Other polyphenolic compounds such as curcumin and resveratrol along with the anti-inflammatory compound, ethyl pyruvate, have displayed antioxidant capabilities that may be clinically useful for treatment of AKI and/or CKD. Curcumin improves kidney function in animal models of AKI by effects that include activating NRF-2 and HO-1 (108, 169, 299). Experiments conducted by our laboratory and others demonstrated the renoprotective effects of resveratrol and ethyl pyruvate in various animal models $(36,37,46,157,174,183$, $243,264)$. In our experiments using mouse models of sepsisand IRI-induced AKI, we observed that the beneficial effects of resveratrol and ethyl pyruvate are attributed to their ability to scavenge ROS and prevent release of proinflammatory HMGB1 in the circulation (242). The renoprotective effects of resveratrol and sulforaphane (an isothiocyanate that is found in vegetables) are also mediated by their ability to upregulate NRF-2 signaling and protect mitochondrial function $(149,153,200,279)$. The upregulation of NRF-2 results in downstream stimulation of various antioxidants, including glutathione, thioredoxin, SOD, and catalase. Thus, these compounds are particularly attractive therapeutics due to their ability to scavenge both ROS and RNS while upregulating numerous antioxidant systems via NRF-2 stimulation.

Many of the naturally occurring compounds still require human studies to determine if they confer any relevant clinical effects for treatment of kidney disease. Indeed, in the case of resveratrol, human studies are currently ongoing. Another NRF-2 activator, bardoxolone methyl, was shown to successfully improve kidney function during AKI and CKD in both animals and humans $(113,229,325)$. However, a phase 3 study, in which bardoxolone methyl was administered to patients with kidney disease, was recently discontinued due to the high toxicity of the drug and an associated increase in mortality.

\section{Ang II blockers}

Other pharmacological agents that have been previously shown to reduce oxidative stress in the kidneys and consequently improve markers of kidney disease are Ang II receptor blockers (141). It is well established that Ang II increases oxidative stress and inflammation, factors that are critically associated with renal pathogenesis, particularly due to hypertension and diabetes $(258,306)$. While infiltrating and resident kidney cells can produce ROS and RNS as a result of Ang II stimulation (7, 68, 133, 193, 225, 255, 256, 259), infiltrating immune cells are also able to directly increase Ang II levels due to their expression of angiotensinogen, angiotensin-converting enzyme, and renin (111). Angiotensinogen expression is enhanced in these cells by NFkB stimulation, an event that is increased by ROS, effectively creating a self-perpetuating positive feedback loop (5). The AT1 receptor modulates the effects of Ang II by 
stimulating NADPH oxidase production of superoxide (5) and mitochondrial ROS generation (155), effects that are exaggerated in CKD animals $(147,303)$. Ang II was also shown to inhibit NRF-2 signaling and reduce the glutathione system in renal epithelial cells (142).

Various AT1 receptor blockers already in use in the clinic for treatment of certain kidney diseases and injuries include losartan, telmisartan, irbesartan, and candesartan. Despite some adverse side effects that sometimes occur with the application of these agents to CKD patients, they are overall effective in improving kidney function and proteinuria. All of these AT1 blockers have been shown to reduce oxidative stress in the kidneys during disease and injury (145, 212, 267), with losartan downregulating expression of NADPH oxidase (9).

\section{Acknowledgments}

Support was received from AHA grant 12SDG9080006, ASN grant 010973-101, The New York Community Trust Renal Clinical Fund (B.B.R.), and NIH grant R01HL115124 (M.S.W.).

\section{References}

1. Centers for Disease Control (CDC). National chronic kidney disease fact sheet: general information and national estimates on chronic kidney disease in the United States, 2014. Department of Health and Human Services, Centers for Disease Control and Prevention, Atlanta, GA. www.cdc.gov/diabetes/pubs/pdf/kidney_factsheet.pdf 11$10-15$

2. Edaravone Acute Infarction Study Group. Effect of a novel free radical scavenger, edaravone (MCI-186), on acute brain infarction. Randomized, placebo-controlled, double-blind study at multicenters. Cerebrovasc Dis 15: 222-229, 2003.

3. Abbate M, Zoja C, and Remuzzi G. How does proteinuria cause progressive renal damage? J Am Soc Nephrol 17: 2974-2984, 2006.

4. Abdelrahman AM, Al Salam S, AlMahruqi AS, Al husseni IS, Mansour MA, and Ali BH. N-acetylcysteine improves renal hemodynamics in rats with cisplatin-induced nephrotoxicity. J Appl Toxicol 30: 15-21, 2010.

5. Agarwal R, Campbell RC, and Warnock DG. Oxidative stress in hypertension and chronic kidney disease: role of angiotensin II. Semin Nephrol 24: 101-114, 2004.

6. Allen IC, Scull MA, Moore CB, Holl EK, McElvaniaTeKippe E, Taxman DJ, Guthrie EH, Pickles RJ, and Ting JP. The NLRP3 inflammasome mediates in vivo innate immunity to influenza A virus through recognition of viral RNA. Immunity 30: 556-565, 2009.

7. Alvarez V, Quiroz Y, Nava M, Pons H, and RodriguezIturbe B. Overload proteinuria is followed by salt-sensitive hypertension caused by renal infiltration of immune cells. Am J Physiol Renal Physiol 283: F1132-F1141, 2002.

8. Araujo $\mathrm{M}$ and Wilcox CS. Oxidative stress in hypertension: role of the kidney. Antioxid Redox Signal 20: 74 101, 2014.

9. Arozal W, Watanabe K, Veeraveedu PT, Ma M, Thandavarayan RA, Suzuki K, Tachikawa $\mathrm{H}$, Kodama M, and Aizawa Y. Effects of angiotensin receptor blocker on oxidative stress and cardio-renal function in streptozotocin-induced diabetic rats. Biol Pharm Bull 32: 1411-1416, 2009.
10. Banday AA and Lokhandwala MF. Dopamine receptors and hypertension. Curr Hypertens Rep 10: 268-275, 2008.

11. Baricos WH, Cortez SL, Deboisblanc M, and Xin S. Transforming growth factor-beta is a potent inhibitor of extracellular matrix degradation by cultured human mesangial cells. J Am Soc Nephrol 10: 790-795, 1999.

12. Baud L, Hagege J, Sraer J, Rondeau E, Perez J, and Ardaillou R. Reactive oxygen production by cultured rat glomerular mesangial cells during phagocytosis is associated with stimulation of lipoxygenase activity. $J$ Exp Med 158: 1836-1852, 1983.

13. Beck KF, Eberhardt W, Frank S, Huwiler A, Messmer UK, Muhl H, and Pfeilschifter J. Inducible NO synthase: role in cellular signalling. J Exp Biol 202: 645-653, 1999.

14. Beck KF, Eberhardt W, Walpen S, Apel M, and Pfeilschifter J. Potentiation of nitric oxide synthase expression by superoxide in interleukin 1 beta-stimulated rat mesangial cells. FEBS Lett 435: 35-38, 1998.

15. Beck KF, Guder G, Schaefer L, Pleskova M, Babelova A, Behrens MH, Mihalik D, Beck M, Schaefer RM, and Pfeilschifter J. Nitric oxide upregulates induction of PDGF receptor-alpha expression in rat renal mesangial cells and in anti-Thy-1 glomerulonephritis. J Am Soc Nephrol 16: 1948-1957, 2005.

16. Beisswenger PJ, Healy JC, and Shultz EK. Glycosylated serum proteins and glycosylated hemoglobin in the assessment of glycemic control in insulin-dependent and non-insulin-dependent diabetes mellitus. Metabolism 42: 989-992, 1993.

17. Bek MJ, Reinhardt HC, Fischer KG, Hirsch JR, Hupfer C, Dayal E, and Pavenstadt H. Up-regulation of early growth response gene-1 via the CXCR3 receptor induces reactive oxygen species and inhibits $\mathrm{Na}+\mathrm{K}+$-ATPase activity in an immortalized human proximal tubule cell line. J Immunol 170: 931-940, 2003.

18. Ben-Nun A, Bashan N, Potashnik R, Cohen-Luria R, and Moran A. Cystine loading induces Fanconi's syndrome in rats: in vivo and vesicle studies. Am J Physiol 265: F839F844, 1993.

19. Bhaskaran M, Reddy K, Radhakrishanan N, Franki N, Ding G, and Singhal PC. Angiotensin II induces apoptosis in renal proximal tubular cells. Am J Physiol Renal Physiol 284: F955-F965, 2003.

20. Block K, Eid A, Griendling KK, Lee DY, Wittrant Y, and Gorin Y. Nox4 NAD(P)H oxidase mediates Src-dependent tyrosine phosphorylation of PDK-1 in response to angiotensin II: role in mesangial cell hypertrophy and fibronectin expression. J Biol Chem 283: 24061-24076, 2008.

21. Block K, Gorin Y, and Abboud HE. Subcellular localization of Nox4 and regulation in diabetes. Proc Natl Acad Sci U S A 106: 14385-14390, 2009.

22. Boaz M, Smetana S, Weinstein T, Matas Z, Gafter U, Iaina A, Knecht A, Weissgarten Y, Brunner D, Fainaru M, and Green MS. Secondary prevention with antioxidants of cardiovascular disease in endstage renal disease (SPACE): randomised placebo-controlled trial. Lancet 356: 12131218, 2000.

23. Bogdan C. Nitric oxide and the regulation of gene expression. Trends Cell Biol 11: 66-75, 2001.

24. Bohler T, Waiser J, Hepburn H, Gaedeke J, Lehmann C, Hambach P, Budde K, and Neumayer HH. TNF-alpha and IL-1alpha induce apoptosis in subconfluent rat mesangial cells. Evidence for the involvement of hydrogen peroxide 
and lipid peroxidation as second messengers. Cytokine 12: 986-991, 2000.

25. Bonventre JV. Mechanisms of ischemic acute renal failure. Kidney Int 43: 1160-1178, 1993.

26. Borutaite V and Brown GC. Caspases are reversibly inactivated by hydrogen peroxide. FEBS Lett 500: 114-118, 2001.

27. Brodsky SV, Gao S, Li H, and Goligorsky MS. Hyperglycemic switch from mitochondrial nitric oxide to superoxide production in endothelial cells. Am J Physiol Heart Circ Physiol 283: H2130-H2139, 2002.

28. Brown GC. Nitric oxide regulates mitochondrial respiration and cell functions by inhibiting cytochrome oxidase. FEBS Lett 369: 136-139, 1995.

29. Cachofeiro V, Goicochea M, de Vinuesa SG, Oubina P, Lahera V, and Luno J. Oxidative stress and inflammation, a link between chronic kidney disease and cardiovascular disease. Kidney Int Suppl: S4-S9, 2008.

30. Carlstrom M, Lai EY, Ma Z, Steege A, Patzak A, Eriksson UJ, Lundberg JO, Wilcox CS, and Persson AE. Superoxide dismutase 1 limits renal microvascular remodeling and attenuates arteriole and blood pressure responses to angiotensin II via modulation of nitric oxide bioavailability. Hypertension 56: 907-913, 2010.

31. Caruso-Neves C, Pinheiro AA, Cai H, Souza-Menezes J, and Guggino WB. PKB and megalin determine the survival or death of renal proximal tubule cells. Proc Natl Acad Sci U S A 103: 18810-18815, 2006.

32. Ceballos-Picot I, Witko-Sarsat V, Merad-Boudia M, Nguyen AT, Thevenin M, Jaudon MC, Zingraff J, Verger $\mathrm{C}$, Jungers $\mathrm{P}$, and Descamps-Latscha B. Glutathione antioxidant system as a marker of oxidative stress in chronic renal failure. Free Radic Biol Med 21: 845-853, 1996.

33. Chabrashvili T, Tojo A, Onozato ML, Kitiyakara C, Quinn MT, Fujita T, Welch WJ, and Wilcox CS. Expression and cellular localization of classic NADPH oxidase subunits in the spontaneously hypertensive rat kidney. Hypertension 39: 269-274, 2002.

34. Chacko BK, Reily C, Srivastava A, Johnson MS, Ye Y, Ulasova E, Agarwal A, Zinn KR, Murphy MP, Kalyanaraman B, and Darley-Usmar V. Prevention of diabetic nephropathy in Ins2(+/)(-)(AkitaJ) mice by the mitochondria-targeted therapy MitoQ. Biochem J 432: 919, 2010.

35. Chander PN, Gealekman O, Brodsky SV, Elitok S, Tojo A, Crabtree M, Gross SS, and Goligorsky MS. Nephropathy in Zucker diabetic fat rat is associated with oxidative and nitrosative stress: prevention by chronic therapy with a peroxynitrite scavenger ebselen. J Am Soc Nephrol 15: 2391-2403, 2004.

36. Chander V and Chopra K. Protective effect of resveratrol, a polyphenolic phytoalexin on glycerol-induced acute renal failure in rat kidney. Ren Fail 28: 161-169, 2006.

37. Chander V, Tirkey N, and Chopra K. Resveratrol, a polyphenolic phytoalexin protects against cyclosporineinduced nephrotoxicity through nitric oxide dependent mechanism. Toxicology 210: 55-64, 2005.

38. Chen J, John R, Richardson JA, Shelton JM, Zhou XJ, Wang Y, Wu QQ, Hartono JR, Winterberg PD, and Lu CY. Toll-like receptor 4 regulates early endothelial activation during ischemic acute kidney injury. Kidney Int 79: 288-299, 2011.

39. Chen J, Park HC, Patschan S, Brodsky SV, Gealikman O, Kuo MC, Li H, Addabbo F, Zhang F, Nasjletti A, Gross
SS, and Goligorsky MS. Premature vascular senescence in metabolic syndrome: could it be prevented and reversed by a selenorganic antioxidant and peroxynitrite scavenger ebselen? Drug Discov Today Ther Strateg 4: 93-99, 2007.

40. Chen Y, McMillan-Ward E, Kong J, Israels SJ, and Gibson SB. Mitochondrial electron-transport-chain inhibitors of complexes I and II induce autophagic cell death mediated by reactive oxygen species. J Cell Sci 120: 41554166, 2007.

41. Chen Y, Pearlman A, Luo Z, and Wilcox CS. Hydrogen peroxide mediates a transient vasorelaxation with tempol during oxidative stress. Am J Physiol Heart Circ Physiol 293: H2085-H2092, 2007.

42. Chen YF, Cowley AW, Jr., and Zou AP. Increased $\mathrm{H}(2) \mathrm{O}(2)$ counteracts the vasodilator and natriuretic effects of superoxide dismutation by tempol in renal medulla. Am J Physiol Regul Integr Comp Physiol 285: R827-R833, 2003.

43. Chirino YI and Pedraza-Chaverri J. Role of oxidative and nitrosative stress in cisplatin-induced nephrotoxicity. Exp Toxicol Pathol 61: 223-242, 2009.

44. Choi K, Kim J, Kim GW, and Choi C. Oxidative stressinduced necrotic cell death via mitochondira-dependent burst of reactive oxygen species. Curr Neurovasc Res 6: 213-222, 2009.

45. Chrysohoou C, Panagiotakos DB, Pitsavos C, Skoumas J, Economou M, Papadimitriou L, and Stefanadis C. The association between pre-hypertension status and oxidative stress markers related to atherosclerotic disease: the ATTICA study. Atherosclerosis 192: 169-176, 2007.

46. Chung KY, Park JJ, and Kim YS. The role of highmobility group box-1 in renal ischemia and reperfusion injury and the effect of ethyl pyruvate. Transplant Proc 40: 2136-2138, 2008.

47. Cimolai MC, Vanasco V, Marchini T, Magnani ND, Evelson $\mathrm{P}$, and Alvarez S. alpha-Lipoic acid protects kidney from oxidative stress and mitochondrial dysfunction associated to inflammatory conditions. Food Funct 5: 3143-3150, 2014.

48. Cohen CD, Grone HJ, Grone EF, Nelson PJ, Schlondorff $\mathrm{D}$, and Kretzler M. Laser microdissection and gene expression analysis on formaldehyde-fixed archival tissue. Kidney Int 61: 125-132, 2002.

49. Cosentino F, Chaff C, and Piedmonte M. Risk factors influencing survival in ICU acute renal failure. Nephrol Dial Transplant 9 Suppl 4: 179-182, 1994.

50. Crabtree MJ, Smith CL, Lam G, Goligorsky MS, and Gross SS. Ratio of 5,6,7,8-tetrahydrobiopterin to 7,8dihydrobiopterin in endothelial cells determines glucoseelicited changes in NO vs. superoxide production by eNOS. Am J Physiol Heart Circ Physiol 294: H1530H1540, 2008.

51. Cruz CM, Rinna A, Forman HJ, Ventura AL, Persechini PM, and Ojcius DM. ATP activates a reactive oxygen species-dependent oxidative stress response and secretion of proinflammatory cytokines in macrophages. $J$ Biol Chem 282: 2871-2879, 2007.

52. Cseko C, Bagi Z, and Koller A. Biphasic effect of hydrogen peroxide on skeletal muscle arteriolar tone via activation of endothelial and smooth muscle signaling pathways. J Appl Physiol (1985) 97: 1130-1137, 2004.

53. D'Amico G and Bazzi C. Pathophysiology of proteinuria. Kidney Int 63: 809-825, 2003. 
54. Danilovic A, Lucon AM, Srougi M, Shimizu MH, Ianhez LE, Nahas WC, and Seguro AC. Protective effect of $\mathrm{N}$-acetylcysteine on early outcomes of deceased renal transplantation. Transplant Proc 43: 1443-1449, 2011.

55. Day BJ. Catalase and glutathione peroxidase mimics. Biochem Pharmacol 77: 285-296, 2009.

56. Deisseroth A and Dounce AL. Catalase: physical and chemical properties, mechanism of catalysis, and physiological role. Physiol Rev 50: 319-375, 1970.

57. Deng Y, Ren X, Yang L, Lin Y, and Wu X. A JNKdependent pathway is required for TNFalpha-induced apoptosis. Cell 115: 61-70, 2003.

58. Dhanarajan R, Abraham P, and Isaac B. Protective effect of ebselen, a selenoorganic drug, against gentamicin-induced renal damage in rats. Basic Clin Pharmacol Toxicol 99: 267-272, 2006.

59. Ding G, Reddy K, Kapasi AA, Franki N, Gibbons N, Kasinath BS, and Singhal PC. Angiotensin II induces apoptosis in rat glomerular epithelial cells. Am J Physiol Renal Physiol 283: F173-F180, 2002.

60. Ding G, Zhang A, Huang S, Pan X, Zhen G, Chen R, and Yang T. ANG II induces c-Jun NH2-terminal kinase activation and proliferation of human mesangial cells via redox-sensitive transactivation of the EGFR. Am J Physiol Renal Physiol 293: F1889-F1897, 2007.

61. Doi K, Suzuki Y, Nakao A, Fujita T, and Noiri E. Radical scavenger edaravone developed for clinical use ameliorates ischemia/reperfusion injury in rat kidney. Kidney Int 65: 1714-1723, 2004.

62. Dreieicher E, Beck KF, Lazaroski S, Boosen M, TsalastraGreul W, Beck M, Fleming I, Schaefer L, and Pfeilschifter J. Nitric oxide inhibits glomerular TGF-beta signaling via SMOC-1. J Am Soc Nephrol 20: 1963-1974, 2009.

63. Eberhardt W, Huwiler A, Beck KF, Walpen S, and Pfeilschifter J. Amplification of IL-1 beta-induced matrix metalloproteinase- 9 expression by superoxide in rat glomerular mesangial cells is mediated by increased activities of NF-kappa B and activating protein-1 and involves activation of the mitogen-activated protein kinase pathways. J Immunol 165: 5788-5797, 2000.

64. Eberhardt W, Kunz D, Hummel R, and Pfeilschifter J. Molecular cloning of the rat inducible nitric oxide synthase gene promoter. Biochem Biophys Res Commun 223: 752-756, 1996.

65. Eberhardt W, Pluss C, Hummel R, and Pfeilschifter J. Molecular mechanisms of inducible nitric oxide synthase gene expression by IL-1beta and cAMP in rat mesangial cells. J Immunol 160: 4961-4969, 1998.

66. Ebrahimian T and Touyz RM. Thioredoxin in vascular biology: role in hypertension. Antioxid Redox Signal 10: 1127-1136, 2008.

67. Eddy AA and Neilson EG. Chronic kidney disease progression. J Am Soc Nephrol 17: 2964-2966, 2006.

68. Endemann D, Touyz RM, Li JS, Deng LY, and Schiffrin EL. Altered angiotensin II-induced small artery contraction during the development of hypertension in spontaneously hypertensive rats. Am J Hypertens 12: 716-723, 1999.

69. Eum HA and Lee SM. Effects of Trolox on the activity and gene expression of cytochrome P450 in hepatic ischemia/reperfusion. Br J Pharmacol 142: 35-42, 2004.

70. Feldman PD and Moises HC. Adrenergic responses of baroreceptive cells in the nucleus tractus solitarii of the rat: a microiontophoretic study. Brain Res 420: 351-361, 1987.

71. Fichtlscherer S, Breuer S, and Zeiher AM. Prognostic value of systemic endothelial dysfunction in patients with acute coronary syndromes: further evidence for the existence of the "vulnerable" patient. Circulation 110: 19261932, 2004.

72. Firuzi O, Miri R, Tavakkoli M, and Saso L. Antioxidant therapy: current status and future prospects. Curr Med Chem 18: 3871-3888, 2011.

73. Folz RJ and Crapo JD. Extracellular superoxide dismutase (SOD3): tissue-specific expression, genomic characterization, and computer-assisted sequence analysis of the human EC SOD gene. Genomics 22: 162-171, 1994.

74. Folz RJ, Guan J, Seldin MF, Oury TD, Enghild JJ, and Crapo JD. Mouse extracellular superoxide dismutase: primary structure, tissue-specific gene expression, chromosomal localization, and lung in situ hybridization. Am J Respir Cell Mol Biol 17: 393-403, 1997.

75. Forbes JM, Coughlan MT, and Cooper ME. Oxidative stress as a major culprit in kidney disease in diabetes. Diabetes 57: 1446-1454, 2008.

76. Foreman JW, Benson LL, Wellons M, Avner ED, Sweeney W, and Nissim I. Metabolic studies of rat renal tubule cells loaded with cystine: the cystine dimethylester model of cystinosis. J Am Soc Nephrol 6: 269-272, 1995.

77. Fujii S, Zhang L, and Kosaka H. Albuminuria, expression of nicotinamide adenine dinucleotide phosphate oxidase and monocyte chemoattractant protein-1 in the renal tubules of hypertensive Dahl salt-sensitive rats. Hypertens Res 30: 991-998, 2007.

78. Fujimoto S, Satoh M, Horike H, Hatta H, Haruna Y, Kobayashi S, Namikoshi T, Arakawa S, Tomita N, and Kashihara N. Olmesartan ameliorates progressive glomerular injury in subtotal nephrectomized rats through suppression of superoxide production. Hypertens Res 31: 305-313, 2008.

79. Fujisawa S, Ishihara M, Atsumi T, and Kadoma Y. A quantitative approach to the free radical interaction between alpha-tocopherol or ascorbate and flavonoids. In Vivo 20: 445-452, 2006.

80. Fukai T. Mitochondrial thioredoxin: novel regulator for NADPH oxidase and angiotensin II-induced hypertension. Hypertension 54: 224-225, 2009.

81. Gailly P, Jouret F, Martin D, Debaix H, Parreira KS, Nishita T, Blanchard A, Antignac C, Willnow TE, Courtoy PJ, Scheinman SJ, Christensen EI, and Devuyst O. A novel renal carbonic anhydrase type III plays a role in proximal tubule dysfunction. Kidney Int 74: 52-61, 2008.

82. Galle J, Herzog C, Schollmeyer P, and Wanner C. Oxygen-derived radicals stimulate renin release of isolated juxtaglomerular cells. FEBS Lett 351: 314-316, 1994.

83. Galle J, Stunz P, Schollmeyer P, and Wanner C. Oxidized LDL and lipoprotein(a) stimulate renin release of juxtaglomerular cells. Kidney Int 47: 45-52, 1995.

84. Gao S, Chen J, Brodsky SV, Huang H, Adler S, Lee JH, Dhadwal N, Cohen-Gould L, Gross SS, and Goligorsky MS. Docking of endothelial nitric oxide synthase (eNOS) to the mitochondrial outer membrane: a pentabasic amino acid sequence in the autoinhibitory domain of eNOS targets a proteinase K-cleavable peptide on the cytoplasmic face of mitochondria. J Biol Chem 279: 15968-15974, 2004. 
85. Gao YJ, Hirota S, Zhang DW, Janssen LJ, and Lee RM. Mechanisms of hydrogen-peroxide-induced biphasic response in rat mesenteric artery. Br J Pharmacol 138: 1085-1092, 2003.

86. Garcia NH, Plato CF, Stoos BA, and Garvin JL. Nitric oxide-induced inhibition of transport by thick ascending limbs from Dahl salt-sensitive rats. Hypertension 34: 508513, 1999.

87. Garvin JL and Hong NJ. Nitric oxide inhibits sodium/ hydrogen exchange activity in the thick ascending limb. Am J Physiol 277: F377-F382, 1999.

88. Garvin JL and Ortiz PA. The role of reactive oxygen species in the regulation of tubular function. Acta Physiol Scand 179: 225-232, 2003.

89. Gauer S, Hauser IA, Obermuller N, Holzmann Y, Geiger $\mathrm{H}$, and Goppelt-Struebe M. Synergistic induction of osteopontin by aldosterone and inflammatory cytokines in mesangial cells. J Cell Biochem 103: 615-623, 2008.

90. Geiszt M, Kopp JB, Varnai P, and Leto TL. Identification of renox, an NAD(P)H oxidase in kidney. Proc Natl Acad Sci U S A 97: 8010-8014, 2000.

91. Genestra M. Oxyl radicals, redox-sensitive signalling cascades and antioxidants. Cell Signal 19: 1807-1819, 2007.

92. Giray B, Kan E, Bali M, Hincal F, and Basaran N. The effect of vitamin $\mathrm{E}$ supplementation on antioxidant enzyme activities and lipid peroxidation levels in hemodialysis patients. Clin Chim Acta 338: 91-98, 2003.

93. Gleyzer N, Vercauteren K, and Scarpulla RC. Control of mitochondrial transcription specificity factors (TFB1M and TFB2M) by nuclear respiratory factors (NRF-1 and NRF-2) and PGC-1 family coactivators. Mol Cell Biol 25: 1354-1366, 2005.

94. Goligorsky MS, Brodsky SV, and Noiri E. Nitric oxide in acute renal failure: NOS versus NOS. Kidney Int 61: 855861,2002

95. Goligorsky MS, Morgan MA, Lyubsky S, Gross RW, Adams DT, and Spitz DR. Establishment of a hydrogen peroxide resistant variant of renal tubular epithelial cells: role of calcium-independent phospholipase A2 in cell damage. Arch Biochem Biophys 301: 119-128, 1993.

96. Goligorsky MS and Noiri E. Duality of nitric oxide in acute renal injury. Semin Nephrol 19: 263-271, 1999.

97. Gorin Y, Ricono JM, Kim NH, Bhandari B, Choudhury GG, and Abboud HE. Nox4 mediates angiotensin IIinduced activation of Akt/protein kinase $\mathrm{B}$ in mesangial cells. Am J Physiol Renal Physiol 285: F219-F229, 2003.

98. Guo Q and Packer L. Ascorbate-dependent recycling of the vitamin E homologue Trolox by dihydrolipoate and glutathione in murine skin homogenates. Free Radic Biol Med 29: 368-374, 2000.

99. Guzy RD, Hoyos B, Robin E, Chen H, Liu L, Mansfield KD, Simon MC, Hammerling U, and Schumacker PT. Mitochondrial complex III is required for hypoxiainduced ROS production and cellular oxygen sensing. Cell Metab 1: 401-408, 2005.

100. Ha H and Lee HB. Reactive oxygen species as glucose signaling molecules in mesangial cells cultured under high glucose. Kidney Int Suppl 77: S19-S25, 2000.

101. Halcox JP, Schenke WH, Zalos G, Mincemoyer R, Prasad A, Waclawiw MA, Nour KR, and Quyyumi AA. Prognostic value of coronary vascular endothelial dysfunction. Circulation 106: 653-658, 2002.
102. Halliwell B and Gutteridge JM. Role of free radicals and catalytic metal ions in human disease: an overview. Methods Enzymol 186: 1-85, 1990.

103. Halliwell B, JMC G. Free Radicals in Biology and Medicine Oxford: Oxford University Press, 1989.

104. Hamilton CA, Brosnan MJ, McIntyre M, Graham D, and Dominiczak AF. Superoxide excess in hypertension and aging: a common cause of endothelial dysfunction. $\mathrm{Hy}$ pertension 37: 529-534, 2001.

105. Han KS, Kang HJ, Kim EY, Yoon WJ, Sohn S, Kwon HJ, and Gwag BJ. 1,2-bis(2-Aminophenoxy)ethane$\mathrm{N}, \mathrm{N}, \mathrm{N}^{\prime}, \mathrm{N}^{\prime}$-tetraacetic acid induces caspase-mediated apoptosis and reactive oxygen species-mediated necrosis in cultured cortical neurons. J Neurochem 78: 230-239, 2001.

106. Hattori Y, Akimoto K, Gross SS, Hattori S, and Kasai K. Angiotensin-II-induced oxidative stress elicits hypoadiponectinaemia in rats. Diabetologia 48: 1066-1074, 2005.

107. Higgins DF, Kimura K, Bernhardt WM, Shrimanker N, Akai Y, Hohenstein B, Saito Y, Johnson RS, Kretzler M, Cohen CD, Eckardt KU, Iwano M, and Haase VH. Hypoxia promotes fibrogenesis in vivo via HIF-1 stimulation of epithelial-to-mesenchymal transition. J Clin Invest 117: 3810-3820, 2007.

108. Hill-Kapturczak N, Thamilselvan V, Liu F, Nick HS, and Agarwal A. Mechanism of heme oxygenase-1 gene induction by curcumin in human renal proximal tubule cells. Am J Physiol Renal Physiol 281: F851-F859, 2001.

109. Himmelfarb J, Ikizler TA, Ellis C, Wu P, Shintani A, Dalal S, Kaplan M, Chonchol M, and Hakim RM. Provision of antioxidant therapy in hemodialysis (PATH): a randomized clinical trial. J Am Soc Nephrol 25: 623-633, 2014.

110. Hoagland KM, Maier KG, and Roman RJ. Contributions of 20-HETE to the antihypertensive effects of Tempol in Dahl salt-sensitive rats. Hypertension 41: 697-702, 2003.

111. Hoch NE, Guzik TJ, Chen W, Deans T, Maalouf SA, Gratze P, Weyand C, and Harrison DG. Regulation of Tcell function by endogenously produced angiotensin II. Am J Physiol Regul Integr Comp Physiol 296: R208R216, 2009.

112. Holterman CE, Thibodeau JF, and Kennedy CR. NADPH oxidase 5 and renal disease. Curr Opin Nephrol Hypertens 24: 81-87, 2015.

113. Hong DS, Kurzrock R, Supko JG, He X, Naing A, Wheler J, Lawrence D, Eder JP, Meyer CJ, Ferguson DA, Mier J, Konopleva M, Konoplev S, Andreeff M, Kufe D, Lazarus H, Shapiro GI, and Dezube BJ. A phase I first-in-human trial of bardoxolone methyl in patients with advanced solid tumors and lymphomas. Clin Cancer Res 18: 33963406, 2012.

114. Hong NJ, Silva GB, and Garvin JL. PKC-alpha mediates flow-stimulated superoxide production in thick ascending limbs. Am J Physiol Renal Physiol 298: F885-F891, 2010.

115. Hoste EA and Schurgers M. Epidemiology of acute kidney injury: how big is the problem? Crit Care Med 36: S146-S151, 2008.

116. Hou SH, Bushinsky DA, Wish JB, Cohen JJ, and Harrington JT. Hospital-acquired renal insufficiency: a prospective study. Am J Med 74: 243-248, 1983.

117. Houkin K, Nakayama N, Kamada K, Noujou T, Abe H, and Kashiwaba T. Neuroprotective effect of the free radical scavenger MCI-186 in patients with cerebral infarction: clinical evaluation using magnetic resonance 
imaging and spectroscopy. J Stroke Cerebrovasc Dis 7: 315-322, 1998.

118. Hruby Z and Beck KF. Cytotoxic effect of autocrine and macrophage-derived nitric oxide on cultured rat mesangial cells. Clin Exp Immunol 107: 76-82, 1997.

119. Hsu SP, Chiang CK, Yang SY, and Chien CT. N-acetylcysteine for the management of anemia and oxidative stress in hemodialysis patients. Nephron Clin Pract 116: c207-c216, 2010.

120. Hu T, Ramachandrarao SP, Siva S, Valancius C, Zhu Y, Mahadev K, Toh I, Goldstein BJ, Woolkalis M, and Sharma K. Reactive oxygen species production via NADPH oxidase mediates TGF-beta-induced cytoskeletal alterations in endothelial cells. Am J Physiol Renal Physiol 289: F816-F825, 2005.

121. Hua P, Feng W, Rezonzew G, Chumley P, and Jaimes EA. The transcription factor ETS-1 regulates angiotensin IIstimulated fibronectin production in mesangial cells. Am J Physiol Renal Physiol 302: F1418-F1429, 2012.

122. Huang HY and Appel LJ. Supplementation of diets with alpha-tocopherol reduces serum concentrations of gammaand delta-tocopherol in humans. J Nutr 133: 3137-3140, 2003.

123. Huwiler A and Pfeilschifter J. Nitric oxide stimulates the stress-activated protein kinase p38 in rat renal mesangial cells. J Exp Biol 202: 655-660, 1999.

124. Hwang I, Lee J, Huh JY, Park J, Lee HB, Ho YS, and Ha H. Catalase deficiency accelerates diabetic renal injury through peroxisomal dysfunction. Diabetes 61: 728-738, 2012.

125. Iacobini C, Menini S, Ricci C, Scipioni A, Sansoni V, Mazzitelli G, Cordone S, Pesce C, Pugliese F, Pricci F, and Pugliese G. Advanced lipoxidation end-products mediate lipid-induced glomerular injury: role of receptormediated mechanisms. J Pathol 218: 360-369, 2009.

126. Iglesias-De La Cruz MC, Ruiz-Torres P, Alcami J, DiezMarques L, Ortega-Velazquez R, Chen S, RodriguezPuyol M, Ziyadeh FN, and Rodriguez-Puyol D. Hydrogen peroxide increases extracellular matrix mRNA through TGF-beta in human mesangial cells. Kidney Int 59: 87-95, 2001.

127. Ishikawa A, Kawarazaki H, Ando K, Fujita M, Fujita T, and Homma Y. Renal preservation effect of ubiquinol, the reduced form of coenzyme Q10. Clin Exp Nephrol 15: 30 33, 2011.

128. Ishola DA, Jr., Post JA, van Timmeren MM, Bakker SJ, Goldschmeding R, Koomans HA, Braam B, and Joles JA. Albumin-bound fatty acids induce mitochondrial oxidant stress and impair antioxidant responses in proximal tubular cells. Kidney Int 70: 724-731, 2006.

129. Islam KN, O'Byrne D, Devaraj S, Palmer B, Grundy SM, and Jialal I. Alpha-tocopherol supplementation decreases the oxidative susceptibility of LDL in renal failure patients on dialysis therapy. Atherosclerosis 150: 217-224, 2000.

130. Isono M, Haneda M, Maeda S, Omatsu-Kanbe M, and Kikkawa R. Atrial natriuretic peptide inhibits endothelin1-induced activation of JNK in glomerular mesangial cells. Kidney Int 53: 1133-1142, 1998.

131. Itani H, Liu X, Sarsour EH, Goswami PC, Born E, Keen HL, and Sigmund CD. Regulation of renin gene expression by oxidative stress. Hypertension 53: 1070-1076, 2009.
132. Jackson MJ, Papa S, Bolanos J, Bruckdorfer R, Carlsen H, Elliott RM, Flier J, Griffiths HR, Heales S, Holst B, Lorusso M, Lund E, Oivind Moskaug J, Moser U, Di Paola M, Polidori MC, Signorile A, Stahl W, Vina-Ribes J, and Astley SB. Antioxidants, reactive oxygen and nitrogen species, gene induction and mitochondrial function. Mol Aspects Med 23: 209-285, 2002.

133. Jameson M, Dai FX, Luscher T, Skopec J, Diederich A, and Diederich D. Endothelium-derived contracting factors in resistance arteries of young spontaneously hypertensive rats before development of overt hypertension. Hypertension 21: 280-288, 1993.

134. Jia J, Ding G, Zhu J, Chen C, Liang W, Franki N, and Singhal PC. Angiotensin II infusion induces nephrin expression changes and podocyte apoptosis. Am J Nephrol 28: 500-507, 2008.

135. Johnson ST, Bigam DL, Emara M, Obaid L, Slack G, Korbutt G, Jewell LD, Van Aerde J, and Cheung PY. Nacetylcysteine improves the hemodynamics and oxidative stress in hypoxic newborn pigs reoxygenated with $100 \%$ oxygen. Shock 28: 484-490, 2007.

136. Jones SA, Hancock JT, Jones OT, Neubauer A, and Topley N. The expression of NADPH oxidase components in human glomerular mesangial cells: detection of protein and mRNA for p47phox, p67phox, and p22phox. $J$ Am Soc Nephrol 5: 1483-1491, 1995.

137. Kagan V, Serbinova E, and Packer L. Antioxidant effects of ubiquinones in microsomes and mitochondria are mediated by tocopherol recycling. Biochem Biophys Res Commun 169: 851-857, 1990.

138. Kagan VE, Serbinova EA, Forte T, Scita G, and Packer L. Recycling of vitamin $\mathrm{E}$ in human low density lipoproteins. J Lipid Res 33: 385-397, 1992.

139. Kagawa T, Takao T, Horino T, Matsumoto R, Inoue K, Morita T, and Hashimoto K. Angiotensin II receptor blocker inhibits tumour necrosis factor-alpha-induced cell damage in human renal proximal tubular epithelial cells. Nephrology (Carlton) 13: 309-315, 2008.

140. Kaimori JY, Takenaka M, Nakajima H, Hamano T, Horio M, Sugaya T, Ito T, Hori M, Okubo K, and Imai E. Induction of glia maturation factor-beta in proximal tubular cells leads to vulnerability to oxidative injury through the p38 pathway and changes in antioxidant enzyme activities. J Biol Chem 278: 33519-33527, 2003.

141. Kalaitzidis R and Bakris GL. Effects of angiotensin II receptor blockers on diabetic nephropathy. J Hypertens Suppl 27: S15-S21, 2009.

142. Kang SJ, You A, and Kwak MK. Suppression of Nrf2 signaling by angiotensin II in murine renal epithelial cells. Arch Pharm Res 34: 829-836, 2011.

143. Kaufman J, Dhakal M, Patel B, and Hamburger R. Community-acquired acute renal failure. Am J Kidney Dis 17: 191-198, 1991.

144. Keller T, Pleskova M, McDonald MC, Thiemermann C, Pfeilschifter $\mathrm{J}$, and Beck KF. Identification of manganese superoxide dismutase as a NO-regulated gene in rat glomerular mesangial cells by 2D gel electrophoresis. Nitric Oxide 9: 183-193, 2003.

145. Khan BV, Navalkar S, Khan QA, Rahman ST, and Parthasarathy S. Irbesartan, an angiotensin type 1 receptor inhibitor, regulates the vascular oxidative state in patients with coronary artery disease. J Am Coll Cardiol 38: 16621667, 2001. 
146. Kim HJ, Kim KW, Yu BP, and Chung HY. The effect of age on cyclooxygenase-2 gene expression: NF-kappaB activation and IkappaBalpha degradation. Free Radic Biol Med 28: 683-692, 2000.

147. Kim HJ, Sato T, Rodriguez-Iturbe B, and Vaziri ND. Role of intrarenal angiotensin system activation, oxidative stress, inflammation, and impaired nuclear factor-erythroid-2-related factor 2 activity in the progression of focal glomerulosclerosis. J Pharmacol Exp Ther 337: 583-590, 2011.

148. Kim J, Seok YM, Jung KJ, and Park KM. Reactive oxygen species/oxidative stress contributes to progression of kidney fibrosis following transient ischemic injury in mice. Am J Physiol Renal Physiol 297: F461-F470, 2009.

149. Kim T, Kim YJ, Han IH, Lee D, Ham J, Kang KS, and Lee JW. The synthesis of sulforaphane analogues and their protection effect against cisplatin induced cytotoxicity in kidney cells. Bioorg Med Chem Lett 25: 62-66, 2015.

150. Kizilgun M, Poyrazoglu Y, Oztas Y, Yaman H, Cakir E, Cayci T, Akgul OE, Kurt YG, Yaren H, Kunak ZI, Macit E, Ozkan E, Taslipinar MY, Turker T, and Ozcan A. Beneficial effects of $\mathrm{N}$-acetylcysteine and ebselen on renal ischemia/reperfusion injury. Ren Fail 33: 512-517, 2011.

151. Klotz LO, Schroeder P, and Sies H. Peroxynitrite signaling: receptor tyrosine kinases and activation of stressresponsive pathways. Free Radic Biol Med 33: 737-743, 2002.

152. Kunz D, Walker G, Eberhardt W, Messmer UK, Huwiler A, and Pfeilschifter J. Platelet-derived growth factor and fibroblast growth factor differentially regulate interleukin 1beta- and cAMP-induced nitric oxide synthase expression in rat renal mesangial cells. J Clin Invest 100: 2800 2809, 1997.

153. Lagouge M, Argmann C, Gerhart-Hines Z, Meziane H, Lerin C, Daussin F, Messadeq N, Milne J, Lambert P, Elliott P, Geny B, Laakso M, Puigserver P, and Auwerx J. Resveratrol improves mitochondrial function and protects against metabolic disease by activating SIRT1 and PGC1alpha. Cell 127: 1109-1122, 2006.

154. Lassegue B, Sorescu D, Szocs K, Yin Q, Akers M, Zhang Y, Grant SL, Lambeth JD, and Griendling KK. Novel gp91(phox) homologues in vascular smooth muscle cells: nox 1 mediates angiotensin II-induced superoxide formation and redox-sensitive signaling pathways. Circ Res 88: 888-894, 2001

155. Lee DY, Wauquier F, Eid AA, Roman LJ, GhoshChoudhury G, Khazim K, Block K, and Gorin Y. Nox4 NADPH oxidase mediates peroxynitrite-dependent uncoupling of endothelial nitric-oxide synthase and fibronectin expression in response to angiotensin II: role of mitochondrial reactive oxygen species. J Biol Chem 288: 28668-28686, 2013.

156. Lee HB, Yu MR, Yang Y, Jiang Z, and Ha H. Reactive oxygen species-regulated signaling pathways in diabetic nephropathy. J Am Soc Nephrol 14: S241-S245, 2003.

157. Leelahavanichkul A, Yasuda H, Doi K, Hu X, Zhou H, Yuen PS, and Star RA. Methyl-2-acetamidoacrylate, an ethyl pyruvate analog, decreases sepsis-induced acute kidney injury in mice. Am J Physiol Renal Physiol 295: F1825-F1835, 2008.

158. Lemasters JJ, Nieminen AL, Qian T, Trost LC, Elmore SP, Nishimura Y, Crowe RA, Cascio WE, Bradham CA, Brenner DA, and Herman B. The mitochondrial perme- ability transition in cell death: a common mechanism in necrosis, apoptosis and autophagy. Biochim Biophys Acta 1366: 177-196, 1998.

159. Li J, Gong Q, Zhong S, Wang L, Guo H, Xiang Y, Ichim TE, Wang CY, Chen S, Gong F, and Chen G. Neutralization of the extracellular HMGB1 released by ischaemic damaged renal cells protects against renal ischaemia-reperfusion injury. Nephrol Dial Transplant 26: 469-478, 2011.

160. Li JM and Shah AM. Endothelial cell superoxide generation: regulation and relevance for cardiovascular pathophysiology. Am J Physiol Regul Integr Comp Physiol 287: R1014-R1030, 2004.

161. Liano F, Junco E, Pascual J, Madero R, and Verde E. The spectrum of acute renal failure in the intensive care unit compared with that seen in other settings. The Madrid Acute Renal Failure Study Group. Kidney Int Suppl 66: S16-S24, 1998.

162. Lifson AR, Hessol NA, Buchbinder SP, O’Malley PM, Barnhart L, Segal M, Katz MH, and Holmberg SD. Serum beta 2-microglobulin and prediction of progression to AIDS in HIV infection. Lancet 339: 1436-1440, 1992.

163. Lin A, Sekhon C, Sekhon B, Smith A, Chavin K, Orak J, Singh I, and Singh A. Attenuation of ischemia-reperfusion injury in a canine model of autologous renal transplantation. Transplantation 78: 654-659, 2004.

164. Liu H, Lo CR, and Czaja MJ. NF-kappaB inhibition sensitizes hepatocytes to TNF-induced apoptosis through a sustained activation of JNK and c-Jun. Hepatology 35: 772-778, 2002.

165. Lodha S, Dani D, Mehta R, Bhaskaran M, Reddy K, Ding $\mathrm{G}$, and Singhal PC. Angiotensin II-induced mesangial cell apoptosis: role of oxidative stress. Mol Med 8: 830-840, 2002.

166. Lu CY, Hartono J, Senitko M, and Chen J. The inflammatory response to ischemic acute kidney injury: a result of the 'right stuff' in the 'wrong place'? Curr Opin Nephrol Hypertens 16: 83-89, 2007.

167. Ludwig M, Utsch B, and Monnens LA. Recent advances in understanding the clinical and genetic heterogeneity of Dent's disease. Nephrol Dial Transplant 21: 2708-2717, 2006.

168. Ma Q. Advances in mechanisms of anti-oxidation. Discov Med 17: 121-130, 2014.

169. Mahmoud AM, Ahmed OM, and Galaly SR. Thymoquinone and curcumin attenuate gentamicin-induced renal oxidative stress, inflammation and apoptosis in rats. $E X$ CLI J 13: 98-110, 2014.

170. Makino A, Skelton MM, Zou AP, and Cowley AW, Jr. Increased renal medullary $\mathrm{H}_{2} \mathrm{O}_{2}$ leads to hypertension. Hypertension 42: 25-30, 2003.

171. Makino A, Skelton MM, Zou AP, Roman RJ, and Cowley $\mathrm{AW}, \mathrm{Jr}$. Increased renal medullary oxidative stress produces hypertension. Hypertension 39: 667-672, 2002.

172. Makita Z, Yanagisawa K, Kuwajima S, Yoshioka N, Atsumi T, Hasunuma Y, and Koike T. Advanced glycation endproducts and diabetic nephropathy. J Diabetes Complications 9: 265-268, 1995.

173. Malhotra JD and Kaufman RJ. Endoplasmic reticulum stress and oxidative stress: a vicious cycle or a doubleedged sword? Antioxid Redox Signal 9: 2277-2293, 2007.

174. Mamelak M and Sowden K. The effect of gammahydroxybutyrate on the H-reflex: pilot study. Neurology 33: 1497-1500, 1983. 
175. Mandel LJ. Metabolic substrates, cellular energy production, and the regulation of proximal tubular transport. Annu Rev Physiol 47: 85-101, 1985.

176. Manning G, Whyte DB, Martinez R, Hunter T, and Sudarsanam $S$. The protein kinase complement of the human genome. Science 298: 1912-1934, 2002.

177. Marklund SL. Extracellular superoxide dismutase and other superoxide dismutase isoenzymes in tissues from nine mammalian species. Biochem J 222: 649-655, 1984.

178. Mates JM. Effects of antioxidant enzymes in the molecular control of reactive oxygen species toxicology. Toxicology 153: 83-104, 2000.

179. Mates JM and Sanchez-Jimenez F. Antioxidant enzymes and their implications in pathophysiologic processes. Front Biosci 4: D339-D345, 1999.

180. Mervaala E, Finckenberg P, Lapatto R, Muller DN, Park JK, Dechend R, Ganten D, Vapaatalo H, and Luft FC. Lipoic acid supplementation prevents angiotensin IIinduced renal injury. Kidney Int 64: 501-508, 2003.

181. Milanesi L, Petrillo M, Sepe L, Boccia A, D’Agostino N, Passamano M, Di Nardo S, Tasco G, Casadio R, and Paolella G. Systematic analysis of human kinase genes: a large number of genes and alternative splicing events result in functional and structural diversity. BMC Bioinformatics 6 Suppl 4: S20, 2005.

182. Minuz P, Patrignani P, Gaino S, Seta F, Capone ML, Tacconelli S, Degan M, Faccini G, Fornasiero A, Talamini G, Tommasoli R, Arosio E, Santonastaso CL, Lechi A, and Patrono C. Determinants of platelet activation in human essential hypertension. Hypertension 43: 64-70, 2004.

183. Miyaji T, Hu X, Yuen PS, Muramatsu Y, Iyer S, Hewitt SM, and Star RA. Ethyl pyruvate decreases sepsis-induced acute renal failure and multiple organ damage in aged mice. Kidney Int 64: 1620-1631, 2003.

184. Miyata K, Rahman M, Shokoji T, Nagai Y, Zhang GX, Sun GP, Kimura S, Yukimura T, Kiyomoto H, Kohno M, Abe Y, and Nishiyama A. Aldosterone stimulates reactive oxygen species production through activation of NADPH oxidase in rat mesangial cells. J Am Soc Nephrol 16: 2906-2912, 2005.

185. Miyata T, Kurokawa K, and Van Ypersele De Strihou C. Advanced glycation and lipoxidation end products: role of reactive carbonyl compounds generated during carbohydrate and lipid metabolism. J Am Soc Nephrol 11: 17441752, 2000.

186. Moist L, Sontrop JM, Gallo K, Mainra R, Cutler M, Freeman D, and House AA. Effect of N-acetylcysteine on serum creatinine and kidney function: results of a randomized controlled trial. Am J Kidney Dis 56: 643-650, 2010.

187. Monnier V, Nemet I, Sell D, and Weiss M. Transition metals and other forms of oxidative protein damage in renal disease. In: Studies on Renal Disorders, edited by Miyata T, Eckardt K, and Nangaku M. New York: Humana Press, 2011, pp. 25-50.

188. Monnier VM, Sell DR, Nagaraj RH, Miyata S, Grandhee $\mathrm{S}$, Odetti $\mathrm{P}$, and Ibrahim SA. Maillard reaction-mediated molecular damage to extracellular matrix and other tissue proteins in diabetes, aging, and uremia. Diabetes 41 Suppl 2: 36-41, 1992.

189. Moreno-Manzano V, Ishikawa Y, Lucio-Cazana J, and Kitamura M. Selective involvement of superoxide anion, but not downstream compounds hydrogen peroxide and peroxynitrite, in tumor necrosis factor-alpha-induced apoptosis of rat mesangial cells. J Biol Chem 275: $12684-$ 12691, 2000.

190. Moriwaki K, Kiyomoto H, Hitomi H, Ihara G, Kaifu K, Matsubara K, Hara T, Kondo N, Ohmori K, Nishiyama A, Fukui T, and Kohno M. Interferon-gamma enhances superoxide production in human mesangial cells via the JAK-STAT pathway. Kidney Int 70: 788-793, 2006.

191. Muhl H and Pfeilschifter J. Amplification of nitric oxide synthase expression by nitric oxide in interleukin 1 betastimulated rat mesangial cells. J Clin Invest 95: 19411946, 1995.

192. Muhl H, Sandau K, Brune B, Briner VA, and Pfeilschifter J. Nitric oxide donors induce apoptosis in glomerular mesangial cells, epithelial cells and endothelial cells. Eur J Pharmacol 317: 137-149, 1996.

193. Nabha L, Garbern JC, Buller CL, and Charpie JR. Vascular oxidative stress precedes high blood pressure in spontaneously hypertensive rats. Clin Exp Hypertens 27: 71-82, 2005.

194. Nakajima H, Takenaka M, Kaimori JY, Hamano T, Iwatani H, Sugaya T, Ito T, Hori M, and Imai E. Activation of the signal transducer and activator of transcription signaling pathway in renal proximal tubular cells by albumin. J Am Soc Nephrol 15: 276-285, 2004.

195. Nakamura Y, Feng Q, Kumagai T, Torikai K, Ohigashi H, Osawa T, Noguchi N, Niki E, and Uchida K. Ebselen, a glutathione peroxidase mimetic seleno-organic compound, as a multifunctional antioxidant. Implication for inflammation-associated carcinogenesis. J Biol Chem 277: 2687-2694, 2002.

196. Nangaku M and Eckardt KU. Hypoxia and the HIF system in kidney disease. J Mol Med (Berl) 85: 1325-1330, 2007.

197. Narita I, Border WA, Ketteler M, and Noble NA. Nitric oxide mediates immunologic injury to kidney mesangium in experimental glomerulonephritis. Lab Invest 72: 17-24, 1995.

198. Nascimento MM, Suliman ME, Silva M, Chinaglia T, Marchioro J, Hayashi SY, Riella MC, Lindholm B, and Anderstam B. Effect of oral N-acetylcysteine treatment on plasma inflammatory and oxidative stress markers in peritoneal dialysis patients: a placebo-controlled study. Perit Dial Int 30: 336-342, 2010.

199. Nash K, Hafeez A, and Hou S. Hospital-acquired renal insufficiency. Am J Kidney Dis 39: 930-936, 2002.

200. Negrette-Guzman M, Huerta-Yepez S, Medina-Campos ON, Zatarain-Barron ZL, Hernandez-Pando R, Torres I, Tapia E, and Pedraza-Chaverri J. Sulforaphane attenuates gentamicin-induced nephrotoxicity: role of mitochondrial protection. Evid Based Complement Alternat Med 2013: 135314, 2013.

201. Newburger PE, Ezekowitz RA, Whitney C, Wright J, and Orkin SH. Induction of phagocyte cytochrome $b$ heavy chain gene expression by interferon gamma. Proc Natl Acad Sci U S A 85: 5215-5219, 1988.

202. Nicolson AG, Haites NE, McKay NG, Wilson HM, MacLeod AM, and Benjamin N. Induction of nitric oxide synthase in human mesangial cells. Biochem Biophys Res Commun 193: 1269-1274, 1993.

203. Nishikawa T, Edelstein D, Du XL, Yamagishi S, Matsumura T, Kaneda Y, Yorek MA, Beebe D, Oates PJ, Hammes HP, Giardino I, and Brownlee M. Normalizing mitochondrial superoxide production blocks three 
pathways of hyperglycaemic damage. Nature 404: 787-790, 2000.

204. Nishinaka Y, Mori H, Endo N, Miyoshi T, Yamashita K, Adachi S, and Arai T. Edaravone directly reacts with singlet oxygen and protects cells from attack. Life Sci 86: 808-813, 2010.

205. Nistala R, Whaley-Connell A, and Sowers JR. Redox control of renal function and hypertension. Antioxid Redox Signal 10: 2047-2089, 2008.

206. Noiri E, Addabbo F, and Goligorsky M. Reactive oxygen and nitrogen species, oxidative and nitrosative stress, and their role in the pathogenesis of acute kidney injury. In: Studies on Renal Disorders, edited by Miyata T, Eckardt K, and Nangaku M. New York: Humana Press, 2011, pp. 161-177.

207. Noiri E, Nakao A, Uchida K, Tsukahara H, Ohno M, Fujita T, Brodsky S, and Goligorsky MS. Oxidative and nitrosative stress in acute renal ischemia. Am J Physiol Renal Physiol 281: F948-F957, 2001.

208. Noiri E, Peresleni T, Miller F, and Goligorsky MS. In vivo targeting of inducible NO synthase with oligodeoxynucleotides protects rat kidney against ischemia. J Clin Invest 97: 2377-2383, 1996.

209. Nozik-Grayck E, Suliman HB, and Piantadosi CA. Extracellular superoxide dismutase. Int J Biochem Cell Biol 37: 2466-2471, 2005.

210. Oberley TD, Coursin DB, Cihla HP, Oberley LW, elSayyad N, and Ho YS. Immunolocalization of manganese superoxide dismutase in normal and transgenic mice expressing the human enzyme. Histochem J 25: 267-279, 1993.

211. Oberley TD, Verwiebe E, Zhong W, Kang SW, and Rhee SG. Localization of the thioredoxin system in normal rat kidney. Free Radic Biol Med 30: 412-424, 2001.

212. Ogawa S, Kobori H, Ohashi N, Urushihara M, Nishiyama A, Mori T, Ishizuka T, Nako K, and Ito S. Angiotensin II type 1 receptor blockers reduce urinary angiotensinogen excretion and the levels of urinary markers of oxidative stress and inflammation in patients with type 2 diabetic nephropathy. Biomark Insights 4: 97-102, 2009.

213. Ohsaki Y, O'Connor P, Mori T, Ryan RP, Dickinson BC, Chang CJ, Lu Y, Ito S, and Cowley AW, Jr. Increase of sodium delivery stimulates the mitochondrial respiratory chain $\mathrm{H}_{2} \mathrm{O}_{2}$ production in rat renal medullary thick ascending limb. Am J Physiol Renal Physiol 302: F95-F102, 2012.

214. Olsson J, Jacobson TA, Paulsson JM, Dadfar E, Moshfegh A, Jacobson SH, and Lundahl J. Expression of neutrophil SOD2 is reduced after lipopolysaccharide stimulation: a potential cause of neutrophil dysfunction in chronic kidney disease. Nephrol Dial Transplant 26: 2195-2201, 2011.

215. Ongajooth L, Ongajyooth S, Likidlilid A, Chantachum Y, Shayakul C, and Nilwarangkur S. Role of lipid peroxidation, trace elements and anti-oxidant enzymes in chronic renal disease patients. J Med Assoc Thai 79: 791800, 1996.

216. Ookawara T, Imazeki N, Matsubara O, Kizaki T, Oh-Ishi S, Nakao C, Sato Y, and Ohno H. Tissue distribution of immunoreactive mouse extracellular superoxide dismutase. Am J Physiol 275: C840-C847, 1998.

217. Orient A, Donko A, Szabo A, Leto TL, and Geiszt M. Novel sources of reactive oxygen species in the human body. Nephrol Dial Transplant 22: 1281-1288, 2007.
218. Ortiz PA and Garvin JL. Role of nitric oxide in the regulation of nephron transport. Am J Physiol Renal Physiol 282: F777-F784, 2002.

219. Ortiz PA, Hong NJ, and Garvin JL. NO decreases thick ascending limb chloride absorption by reducing $\mathrm{Na}(+)$ $\mathrm{K}(+)-2 \mathrm{Cl}(-)$ cotransporter activity. Am J Physiol Renal Physiol 281: F819-F825, 2001.

220. Ortiz PA, Hong NJ, Wang D, and Garvin JL. Gene transfer of eNOS to the thick ascending limb of eNOS-KO mice restores the effects of L-arginine on $\mathrm{NaCl}$ absorption. Hypertension 42: 674-679, 2003.

221. Osman B, Doller A, Akool el S, Holdener M, Hintermann E, Pfeilschifter J, and Eberhardt W. Rapamycin induces the TGFbeta1/Smad signaling cascade in renal mesangial cells upstream of mTOR. Cell Signal 21: 1806-1817, 2009.

222. Ott M, Zhivotovsky B, and Orrenius S. Role of cardiolipin in cytochrome c release from mitochondria. Cell Death Differ 14: 1243-1247, 2007.

223. Ozgur T, Tutanc M, Zararsiz I, Motor S, Ozturk OH, Yaldiz M, and Kurtgoz OY. The protective effect of ebselen on radiocontrast-induced nephrotoxicity. Ren Fail 34: 991-997, 2012.

224. Panico C, Luo Z, Damiano S, Artigiano F, Gill P, and Welch WJ. Renal proximal tubular reabsorption is reduced in adult spontaneously hypertensive rats: roles of superoxide and $\mathrm{Na}+\mathrm{H}+$ exchanger 3. Hypertension 54: 1291-1297, 2009.

225. Park JB, Touyz RM, Chen X, and Schiffrin EL. Chronic treatment with a superoxide dismutase mimetic prevents vascular remodeling and progression of hypertension in salt-loaded stroke-prone spontaneously hypertensive rats. Am J Hypertens 15: 78-84, 2002.

226. Paul JL, Man NK, Moatti N, and Raichvarg D. [Membrane phospholipid peroxidation in renal insufficiency and chronic hemodialysis]. Nephrologie 12: 4-7, 1991.

227. Peppa M, Uribarri J, Cai W, Lu M, and Vlassara H. Glycoxidation and inflammation in renal failure patients. Am J Kidney Dis 43: 690-695, 2004.

228. Peresleni T, Noiri E, Bahou WF, and Goligorsky MS. Antisense oligodeoxynucleotides to inducible NO synthase rescue epithelial cells from oxidative stress injury. Am J Physiol 270: F971-F977, 1996.

229. Pergola PE, Krauth M, Huff JW, Ferguson DA, Ruiz S, Meyer CJ, and Warnock DG. Effect of bardoxolone methyl on kidney function in patients with T2D and Stage 3b-4 CKD. Am J Nephrol 33: 469-476, 2011.

230. Pfeilschifter $\mathbf{J}$ and Beck K. Oxidative stress injury in glomerular mesangium. In: Studies on Renal Disorders, edited by Miyata T, Eckardt K, and Nangaku M. New York: Humana Press, 2011, pp. 3-23.

231. Pfeilschifter J, Beck KF, Eberhardt W, and Huwiler A. Changing gears in the course of glomerulonephritis by shifting superoxide to nitric oxide-dominated chemistry. Kidney Int 61: 809-815, 2002.

232. Pfeilschifter J, Eberhardt W, and Beck KF. Regulation of gene expression by nitric oxide. Pflugers Arch 442: 479486, 2001.

233. Pfeilschifter J, Eberhardt W, Beck KF, and Huwiler A. Redox signaling in mesangial cells. Nephron Exp Nephrol 93: e23-e26, 2003.

234. Pfeilschifter J, Eberhardt W, and Huwiler A. Nitric oxide and mechanisms of redox signaling. J Am Soc Nephrol 14: S237-S240, 2003. 
235. Piantadosi CA and Suliman HB. Mitochondrial transcription factor A induction by redox activation of nuclear respiratory factor 1. J Biol Chem 281: 324-333, 2006.

236. Pieczenik SR and Neustadt J. Mitochondrial dysfunction and molecular pathways of disease. Exp Mol Pathol 83: 84-92, 2007.

237. Pleskova M, Beck KF, Behrens MH, Huwiler A, Fichtlscherer $\mathrm{B}$, Wingerter $\mathrm{O}$, Brandes RP, Mulsch A, and Pfeilschifter J. Nitric oxide down-regulates the expression of the catalytic NADPH oxidase subunit Nox1 in rat renal mesangial cells. FASEB J 20: 139-141, 2006.

238. Polla BS, Bachelet M, Elia G, and Santoro MG. Stress proteins in inflammation. Ann N Y Acad Sci 851: 75-85, 1998.

239. Poss KD and Tonegawa S. Reduced stress defense in heme oxygenase 1-deficient cells. Proc Natl Acad Sci U S A 94: 10925-10930, 1997.

240. Preethi KC and Kuttan R. Hepato and reno protective action of Calendula officinalis L. flower extract. Indian $J$ Exp Biol 47: 163-168, 2009.

241. Pushpa-Rekha TR, Burdsall AL, Oleksa LM, Chisolm GM, and Driscoll DM. Rat phospholipid-hydroperoxide glutathione peroxidase. cDNA cloning and identification of multiple transcription and translation start sites. $J$ Biol Chem 270: 26993-26999, 1995.

242. Rabadi MM, Ghaly T, Goligorksy MS, and Ratliff BB. HMGB1 in renal ischemic injury. Am J Physiol Renal Physiol 303: F873-F885, 2012.

243. Rabadi MM, Xavier S, Vasko R, Kaur K, Goligorksy MS, and Ratliff BB. High-mobility group box 1 is a novel deacetylation target of Sirtuin1. Kidney Int 87: 95-108, 2015.

244. Radeke HH, Cross AR, Hancock JT, Jones OT, Nakamura M, Kaever V, and Resch K. Functional expression of NADPH oxidase components (alpha- and beta-subunits of cytochrome b558 and $45-\mathrm{kDa}$ flavoprotein) by intrinsic human glomerular mesangial cells. J Biol Chem 266: 21025-21029, 1991.

245. Radeke HH, Meier B, Topley N, Floge J, Habermehl GG, and Resch K. Interleukin 1-alpha and tumor necrosis factor-alpha induce oxygen radical production in mesangial cells. Kidney Int 37: 767-775, 1990.

246. Rahman I, Marwick J, and Kirkham P. Redox modulation of chromatin remodeling: impact on histone acetylation and deacetylation, NF-kappaB and pro-inflammatory gene expression. Biochem Pharmacol 68: 1255-1267, 2004.

247. Ramesh G and Reeves WB. p38 MAP kinase inhibition ameliorates cisplatin nephrotoxicity in mice. Am J Physiol Renal Physiol 289: F166-F174, 2005.

248. Rech VC, Feksa LR, Arevalo do Amaral MF, Koch GW, Wajner M, Dutra-Filho CS, Terezinha de Souza Wyse A, and Duval Wannmacher CM. Promotion of oxidative stress in kidney of rats loaded with cystine dimethyl ester. Pediatr Nephrol 22: 1121-1128, 2007.

249. Redon J, Oliva MR, Tormos C, Giner V, Chaves J, Iradi A, and Saez GT. Antioxidant activities and oxidative stress byproducts in human hypertension. Hypertension 41: 1096-1101, 2003.

250. Ren Y, D’Ambrosio MA, Liu R, Pagano PJ, Garvin JL, and Carretero OA. Enhanced myogenic response in the afferent arteriole of spontaneously hypertensive rats. Am J Physiol Heart Circ Physiol 298: H1769-H1775, 2010.

251. Ren Z, Liang W, Chen C, Yang H, Singhal PC, and Ding G. Angiotensin II induces nephrin dephosphorylation and podocyte injury: role of caveolin-1. Cell Signal 24: 443450, 2012.

252. Renke M, Tylicki L, Rutkowski P, Larczynski W, Aleksandrowicz E, Lysiak-Szydlowska W, and Rutkowski B. The effect of $\mathrm{N}$-acetylcysteine on proteinuria and markers of tubular injury in non-diabetic patients with chronic kidney disease. A placebo-controlled, randomized, open, cross-over study. Kidney Blood Press Res 31: 404-410, 2008.

253. Robey RB and Hay N. Mitochondrial hexokinases, novel mediators of the antiapoptotic effects of growth factors and Akt. Oncogene 25: 4683-4696, 2006.

254. Roche M, Rondeau P, Singh NR, Tarnus E, and Bourdon E. The antioxidant properties of serum albumin. FEBS Lett 582: 1783-1787, 2008.

255. Rodriguez-Iturbe B, Pons H, Quiroz Y, Gordon K, Rincon J, Chavez M, Parra G, Herrera-Acosta J, Gomez-Garre D, Largo R, Egido J, and Johnson RJ. Mycophenolate mofetil prevents salt-sensitive hypertension resulting from angiotensin II exposure. Kidney Int 59: 2222-2232, 2001.

256. Rodriguez-Iturbe B, Quiroz Y, Nava M, Bonet L, Chavez M, Herrera-Acosta J, Johnson RJ, and Pons HA. Reduction of renal immune cell infiltration results in blood pressure control in genetically hypertensive rats. Am J Physiol Renal Physiol 282: F191-F201, 2002.

257. Rodriguez-Iturbe B, Sepassi L, Quiroz Y, Ni Z, Wallace DC, and Vaziri ND. Association of mitochondrial SOD deficiency with salt-sensitive hypertension and accelerated renal senescence. J Appl Physiol (1985) 102: 255-260, 2007.

258. Rodriguez-Iturbe B, Vaziri ND, Herrera-Acosta J, and Johnson RJ. Oxidative stress, renal infiltration of immune cells, and salt-sensitive hypertension: all for one and one for all. Am J Physiol Renal Physiol 286: F606-F616, 2004.

259. Rodriguez-Iturbe B, Zhan CD, Quiroz Y, Sindhu RK, and Vaziri ND. Antioxidant-rich diet relieves hypertension and reduces renal immune infiltration in spontaneously hypertensive rats. Hypertension 41: 341-346, 2003.

260. Rosen H, Crowley JR, and Heinecke JW. Human neutrophils use the myeloperoxidase-hydrogen peroxidechloride system to chlorinate but not nitrate bacterial proteins during phagocytosis. J Biol Chem 277: 3046330468, 2002.

261. Ryter SW, Kim HP, Hoetzel A, Park JW, Nakahira K, Wang X, and Choi AM. Mechanisms of cell death in oxidative stress. Antioxid Redox Signal 9: 49-89, 2007.

262. Sachse A and Wolf G. Angiotensin II-induced reactive oxygen species and the kidney. J Am Soc Nephrol 18: 2439-2446, 2007.

263. Saez GT, Tormos C, Giner V, Chaves J, Lozano JV, Iradi A, and Redon J. Factors related to the impact of antihypertensive treatment in antioxidant activities and oxidative stress by-products in human hypertension. Am J Hypertens 17: 809-816, 2004.

264. Saito M, Satoh S, Kojima N, Tada H, Sato M, Suzuki T, Senoo H, and Habuchi T. Effects of a phenolic compound, resveratrol, on the renal function and costimulatory adhesion molecule CD86 expression in rat kidneys with ischemia/reperfusion injury. Arch Histol Cytol 68: 41-49, 2005.

265. Sandau K, Pfeilschifter J, and Brune B. The balance between nitric oxide and superoxide determines apoptotic 
and necrotic death of rat mesangial cells. J Immunol 158: 4938-4946, 1997.

266. Sathiyapriya V, Nandeesha H, Bobby Z, Selvaraj N, and Pavithran P. Perturbation of oxidant-antioxidant status in non-obese prehypertensive male subjects. J Hum $\mathrm{Hy}$ pertens 21: 176-178, 2007.

267. Sato-Horiguchi C, Ogawa D, Wada J, Tachibana H, Kodera R, Eguchi J, Nakatsuka A, Terami N, Shikata K, and Makino H. Telmisartan attenuates diabetic nephropathy by suppressing oxidative stress in $\mathrm{db} / \mathrm{db}$ mice. Nephron Exp Nephrol 121: e97-e108, 2012.

268. Satriano J, Lortie MJ, Ishizuka S, Valdivielso JM, Friedman B, and Munger KA. Inhibition of inducible nitric oxide synthase alters Thy-1 glomeruonephritis in rats. Nephron Physiol 102: 17-26, 2006.

269. Satriano JA, Banas B, Luckow B, Nelson P, and Schlondorff DO. Regulation of RANTES and ICAM-1 expression in murine mesangial cells. J Am Soc Nephrol 8: 596-603, 1997.

270. Schaefer L, Beck KF, Raslik I, Walpen S, Mihalik D, Micegova M, Macakova K, Schonherr E, Seidler DG, Varga G, Schaefer RM, Kresse H, and Pfeilschifter J. Biglycan, a nitric oxide-regulated gene, affects adhesion, growth, and survival of mesangial cells. J Biol Chem 278: 26227-26237, 2003.

271. Schieber M and Chandel NS. ROS function in redox signaling and oxidative stress. Curr Biol 24: R453-R462, 2014.

272. Schiraldi M, Raucci A, Munoz LM, Livoti E, Celona B, Venereau E, Apuzzo T, De Marchis F, Pedotti M, Bachi A, Thelen M, Varani L, Mellado M, Proudfoot A, Bianchi $\mathrm{ME}$, and Uguccioni M. HMGB1 promotes recruitment of inflammatory cells to damaged tissues by forming a complex with CXCL12 and signaling via CXCR4. J Exp Med 209: 551-563, 2012.

273. Schmidt AM, Hofmann M, Taguchi A, Yan SD, and Stern DM. RAGE: a multiligand receptor contributing to the cellular response in diabetic vasculopathy and inflammation. Semin Thromb Hemost 26: 485-493, 2000.

274. Schreck C and O'Connor PM. NAD(P)H oxidase and renal epithelial ion transport. Am J Physiol Regul Integr Comp Physiol 300: R1023-R1029, 2011.

275. Sehirli O, Sener E, Cetinel S, Yuksel M, Gedik N, and Sener G. Alpha-lipoic acid protects against renal ischaemiareperfusion injury in rats. Clin Exp Pharmacol Physiol 35: 249-255, 2008.

276. Sen CK and Packer L. Antioxidant and redox regulation of gene transcription. FASEB J 10: 709-720, 1996.

277. Serbinova E, Kagan V, Han D, and Packer L. Free radical recycling and intramembrane mobility in the antioxidant properties of alpha-tocopherol and alpha-tocotrienol. Free Radic Biol Med 10: 263-275, 1991.

278. Shalamanova L, McArdle F, Amara AB, Jackson MJ, and Rustom R. Albumin overload induces adaptive responses in human proximal tubular cells through oxidative stress but not via angiotensin II type 1 receptor. Am J Physiol Renal Physiol 292: F1846-F1857, 2007.

279. Shang G, Tang X, Gao P, Guo F, Liu H, Zhao Z, Chen Q, Jiang T, Zhang N, and Li H. Sulforaphane attenuation of experimental diabetic nephropathy involves GSK-3 beta/ Fyn/Nrf2 signaling pathway. J Nutr Biochem 26: 596606, 2015.

280. Shibata S, Nagase M, Yoshida S, Kawachi H, and Fujita T. Podocyte as the target for aldosterone: roles of oxidative stress and Sgk1. Hypertension 49: 355-364, 2007.
281. Shiose A, Kuroda J, Tsuruya K, Hirai M, Hirakata H, Naito S, Hattori M, Sakaki Y, and Sumimoto H. A novel superoxide-producing $\mathrm{NAD}(\mathrm{P}) \mathrm{H}$ oxidase in kidney. J Biol Chem 276: 1417-1423, 2001.

282. Shurtz-Swirski R, Mashiach E, Kristal B, Shkolnik T, and Shasha SM. Antioxidant enzymes activity in polymorphonuclear leukocytes in chronic renal failure. Nephron 71: 176-179, 1995.

283. Shusterman N, Strom BL, Murray TG, Morrison G, West SL, and Maislin G. Risk factors and outcome of hospitalacquired acute renal failure. Clinical epidemiologic study. Am J Med 83: 65-71, 1987.

284. Silva GB, Ortiz PA, Hong NJ, and Garvin JL. Superoxide stimulates $\mathrm{NaCl}$ absorption in the thick ascending limb via activation of protein kinase C. Hypertension 48: 467-472, 2006.

285. Simic DV, Mimic-Oka J, Pljesa-Ercegovac M, Savic-Radojevic A, Opacic M, Matic D, Ivanovic B, and Simic T. Byproducts of oxidative protein damage and antioxidant enzyme activities in plasma of patients with different degrees of essential hypertension. J Hum Hypertens 20: 149-155, 2006.

286. Sousa T, Oliveira S, Afonso J, Morato M, Patinha D, Fraga S, Carvalho F, Albino-and Teixeira A. Role of $\mathrm{H}(2) \mathrm{O}(2)$ in hypertension, renin-angiotensin system activation and renal medullary disfunction caused by angiotensin II. Br J Pharmacol 166: 2386-2401, 2012.

287. Sousa T, Pinho D, Morato M, Marques-Lopes J, Fernandes E, Afonso J, Oliveira S, Carvalho F, and AlbinoTeixeira A. Role of superoxide and hydrogen peroxide in hypertension induced by an antagonist of adenosine receptors. Eur J Pharmacol 588: 267-276, 2008.

288. Stier CT, Jr., Itskovitz HD, and Chen YH. Urinary dopamine and sodium excretion in spontaneously hypertensive rats. Clin Exp Hypertens 15: 105-123, 1993.

289. Strutz FM. EMT and proteinuria as progression factors. Kidney Int 75: 475-481, 2009.

290. Sugimoto T, Kikkawa R, Haneda M, Araki S, Koya D, Togawa M, and Shigeta Y. Cyclic nucleotides attenuate endothelin-1-induced activation of mitogen-activated protein kinase in cultured rat mesangial cells. J Diabetes Complications 9: 249-251, 1995.

291. Sun P, Yue P, and Wang WH. Angiotensin II stimulates epithelial sodium channels in the cortical collecting duct of the rat kidney. Am J Physiol Renal Physiol 302: F679F687, 2012.

292. Sverrisson K, Axelsson J, Rippe A, Asgeirsson D, and Rippe B. Acute reactive oxygen species (ROS)-dependent effects of IL-1beta, TNF-alpha, and IL-6 on the glomerular filtration barrier (GFB) in vivo. Am J Physiol Renal Physiol 309: F800-F806, 2015.

293. Terryn S and Devuyst O. Oxidative stress in the kidney: proximal tubule disorders. In: Studies on Renal Disorders, edited by Miyata T, Eckardt K, and Nangaku M. New York: Humana Press, 2011, pp. 179-203.

294. Thaete LG, Crouch RK, Schulte BA, and Spicer SS. The immunolocalization of copper-zinc superoxide dismutase in canine tissues. J Histochem Cytochem 31: 1399-1406, 1983.

295. Thaete LG, Crouch RK, and Spicer SS. Immunolocalization of copper-zinc superoxide dismutase. II. Rat. J Histochem Cytochem 33: 803-808, 1985.

296. Thallas-Bonke V, Jandeleit-Dahm KA, and Cooper ME. Nox-4 and progressive kidney disease. Curr Opin Nephrol Hypertens 24: 74-80, 2015. 
297. Thevenod F. Cadmium and cellular signaling cascades: to be or not to be? Toxicol Appl Pharmacol 238: 221-239, 2009.

298. Thomas SR, Witting PK, and Drummond GR. Redox control of endothelial function and dysfunction: molecular mechanisms and therapeutic opportunities. Antioxid Redox Signal 10: 1713-1765, 2008.

299. Ugur S, Ulu R, Dogukan A, Gurel A, Yigit IP, Gozel N, Aygen B, and Ilhan N. The renoprotective effect of curcumin in cisplatin-induced nephrotoxicity. Ren Fail 37: 332-336, 2015.

300. Valko M, Leibfritz D, Moncol J, Cronin MT, Mazur M, and Telser J. Free radicals and antioxidants in normal physiological functions and human disease. Int J Biochem Cell Biol 39: 44-84, 2007.

301. Vasko R and Goligorsky MS. Dysfunctional lysosomal autophagy leads to peroxisomal oxidative burnout and damage during endotoxin-induced stress. Autophagy 9: 442-444, 2013.

302. Vasko R, Ratliff BB, Bohr S, Nadel E, Chen J, Xavier S, Chander P, and Goligorsky MS. Endothelial peroxisomal dysfunction and impaired pexophagy promotes oxidative damage in lipopolysaccharide-induced acute kidney injury. Antioxid Redox Signal 19: 211-230, 2013.

303. Vaziri ND, Dicus M, Ho ND, Boroujerdi-Rad L, and Sindhu RK. Oxidative stress and dysregulation of superoxide dismutase and NADPH oxidase in renal insufficiency. Kidney Int 63: 179-185, 2003.

304. Vaziri ND, Ni Z, Oveisi F, Liang K, and Pandian R. Enhanced nitric oxide inactivation and protein nitration by reactive oxygen species in renal insufficiency. Hypertension 39: 135-141, 2002.

305. Vaziri ND, Oveisi F, and Ding Y. Role of increased oxygen free radical activity in the pathogenesis of uremic hypertension. Kidney Int 53: 1748-1754, 1998.

306. Vaziri ND and Rodriguez-Iturbe B. Mechanisms of disease: oxidative stress and inflammation in the pathogenesis of hypertension. Nat Clin Pract Nephrol 2: 582-593, 2006.

307. Venereau E, Casalgrandi M, Schiraldi M, Antoine DJ, Cattaneo A, De Marchis F, Liu J, Antonelli A, Preti A, Raeli L, Shams SS, Yang H, Varani L, Andersson U, Tracey KJ, Bachi A, Uguccioni M, and Bianchi ME. Mutually exclusive redox forms of HMGB1 promote cell recruitment or proinflammatory cytokine release. J Exp Med 209: 1519-1528, 2012.

308. Verma PK, Raina R, Sultana M, Singh M, and Kumar P. Total antioxidant and oxidant status of plasma and renal tissue of cisplatin-induced nephrotoxic rats: protection by floral extracts of Calendula officinalis Linn. Ren Fail 38: 142-150, 2016.

309. Vetter M, Chen ZJ, Chang GD, Che D, Liu S, and Chang $\mathrm{CH}$. Cyclosporin A disrupts bradykinin signaling through superoxide. Hypertension 41: 1136-1142, 2003.

310. Vezzoli M, Castellani P, Corna G, Castiglioni A, Bosurgi L, Monno A, Brunelli S, Manfredi AA, Rubartelli A, and Rovere-Querini P. High-mobility group box 1 release and redox regulation accompany regeneration and remodeling of skeletal muscle. Antioxid Redox Signal 15: 2161-2174, 2011.

311. Visarius TM, Putt DA, Schare JM, Pegouske DM, and Lash LH. Pathways of glutathione metabolism and transport in isolated proximal tubular cells from rat kidney. Biochem Pharmacol 52: 259-272, 1996.
312. Vossler S, Fullert S, Schneider F, Haak E, Haak T, Samigullin $\mathrm{R}$, Tritschler $\mathrm{H}$, Tooke JE, and Konrad $\mathrm{T}$. Pharmacodynamic effects of orally administered dexlipotam on endothelial function in type 2-diabetic patients. Int J Clin Pharmacol Ther 45: 385-393, 2007.

313. Walpen S, Beck KF, Schaefer L, Raslik I, Eberhardt W, Schaefer RM, and Pfeilschifter J. Nitric oxide induces MIP-2 transcription in rat renal mesangial cells and in a rat model of glomerulonephritis. FASEB J 15: 571-573, 2001.

314. Wang D, Strandgaard S, Iversen J, and Wilcox CS. Asymmetric dimethylarginine, oxidative stress, and vascular nitric oxide synthase in essential hypertension. Am J Physiol Regul Integr Comp Physiol 296: R195-R200, 2009.

315. Wang W, Fang H, Groom L, Cheng A, Zhang W, Liu J, Wang X, Li K, Han P, Zheng M, Yin J, Mattson MP, Kao JP, Lakatta EG, Sheu SS, Ouyang K, Chen J, Dirksen RT, and Cheng H. Superoxide flashes in single mitochondria. Cell 134: 279-290, 2008.

316. Weinberg JB, Granger DL, Pisetsky DS, Seldin MF, Misukonis MA, Mason SN, Pippen AM, Ruiz P, Wood $\mathrm{ER}$, and Gilkeson GS. The role of nitric oxide in the pathogenesis of spontaneous murine autoimmune disease: increased nitric oxide production and nitric oxide synthase expression in MRL-lpr/lpr mice, and reduction of spontaneous glomerulonephritis and arthritis by orally administered NG-monomethyl-L-arginine. J Exp Med 179: 651-660, 1994.

317. Welch WJ, Baumgartl H, Lubbers D, and Wilcox CS. Nephron pO2 and renal oxygen usage in the hypertensive rat kidney. Kidney Int 59: 230-237, 2001.

318. Westenfeld R, Gawlik A, de Heer E, Kitahara M, AbouRebyeh F, Floege J, and Ketteler M. Selective inhibition of inducible nitric oxide synthase enhances intraglomerular coagulation in chronic anti-Thy 1 nephritis. Kidney Int 61: 834-838, 2002.

319. Wilcox CS. Oxidative stress and nitric oxide deficiency in the kidney: a critical link to hypertension? Am J Physiol Regul Integr Comp Physiol 289: R913-R935, 2005.

320. Williams JM, Sarkis A, Hoagland KM, Fredrich K, Ryan RP, Moreno C, Lopez B, Lazar J, Fenoy FJ, Sharma M, Garrett MR, Jacob HJ, and Roman RJ. Transfer of the CYP4A region of chromosome 5 from Lewis to Dahl $\mathrm{S}$ rats attenuates renal injury. Am J Physiol Renal Physiol 295: F1764-F1777, 2008.

321. Wilmer MJ, de Graaf-Hess A, Blom HJ, Dijkman HB, Monnens LA, van den Heuvel LP, and Levtchenko EN. Elevated oxidized glutathione in cystinotic proximal tubular epithelial cells. Biochem Biophys Res Commun 337: 610-614, 2005.

322. Wolf G, Hannken T, Schroeder R, Zahner G, Ziyadeh FN, and Stahl RA. Antioxidant treatment induces transcription and expression of transforming growth factor beta in cultured renal proximal tubular cells. FEBS Lett 488: 154159, 2001.

323. Wongmekiat $\mathrm{O}$, Thamprasert $\mathrm{K}$, and Lumlertgul D. Renoprotective effect of trolox against ischaemia-reperfusion injury in rats. Clin Exp Pharmacol Physiol 34: 753-759, 2007.

324. Wu H, Ma J, Wang P, Corpuz TM, Panchapakesan U, Wyburn KR, and Chadban SJ. HMGB1 contributes to kidney ischemia reperfusion injury. J Am Soc Nephrol 21: 1878-1890, 2010. 
325. Wu J, Liu X, Fan J, Chen W, Wang J, Zeng Y, Feng X, Yu $\mathrm{X}$, and Yang X. Bardoxolone methyl (BARD) ameliorates aristolochic acid (AA)-induced acute kidney injury through Nrf2 pathway. Toxicology 318: 22-31, 2014.

326. Wu Z, Puigserver P, Andersson U, Zhang C, Adelmant G, Mootha V, Troy A, Cinti S, Lowell B, Scarpulla RC, and Spiegelman BM. Mechanisms controlling mitochondrial biogenesis and respiration through the thermogenic coactivator PGC-1. Cell 98: 115-124, 1999.

327. Xie QW, Whisnant R, and Nathan C. Promoter of the mouse gene encoding calcium-independent nitric oxide synthase confers inducibility by interferon gamma and bacterial lipopolysaccharide. J Exp Med 177: 1779-1784, 1993.

328. Yadav A, Vallabu S, Arora S, Tandon P, Slahan D, Teichberg S, and Singhal PC. ANG II promotes autophagy in podocytes. Am J Physiol Cell Physiol 299: C488-C496, 2010.

329. Yang C. Infection in the kidney. In: Studies on Renal Disorders, edited by Miyata T, Eckardt K, and Nangaku M. New York: Humana Press, 2011, pp. 293-304.

330. Yang QW, Lu FL, Zhou Y, Wang L, Zhong Q, Lin S, Xiang J, Li JC, Fang CQ, and Wang JZ. HMBG1 mediates ischemia-reperfusion injury by TRIF-adaptor independent Toll-like receptor 4 signaling. J Cereb Blood Flow Metab 31: 593-605, 2011.

331. Yasunari K, Maeda K, Nakamura M, and Yoshikawa J. Oxidative stress in leukocytes is a possible link between blood pressure, blood glucose, and C-reacting protein. Hypertension 39: 777-780, 2002.

332. Ye J, Li J, Yu Y, Wei Q, Deng W, and Yu L. L-carnitine attenuates oxidant injury in HK-2 cells via ROS-mitochondria pathway. Regul Pept 161: 58-66, 2010.

333. Yi X, Nickeleit V, James LR, and Maeda N. alpha-Lipoic acid protects diabetic apolipoprotein E-deficient mice from nephropathy. J Diabetes Complications 25: 193201, 2011.

334. Yilmaz MI, Saglam M, Caglar K, Cakir E, Sonmez A, Ozgurtas T, Aydin A, Eyileten T, Ozcan O, Acikel C, Tasar M, Genctoy G, Erbil K, Vural A, and Zoccali C. The determinants of endothelial dysfunction in CKD: oxidative stress and asymmetric dimethylarginine. Am J Kidney Dis 47: 42-50, 2006.

335. Yoshimura M, Kambara S, Okabayashi H, Takahashi H, and Ijichi $\mathrm{H}$. Effect of decreased dopamine synthesis on the development of hypertension induced by salt loading in spontaneously hypertensive rats. Clin Exp Hypertens $A$ 9: 1141-1157, 1987.

336. Yu L, Bao HF, Self JL, Eaton DC, and Helms MN. Aldosterone-induced increases in superoxide production counters nitric oxide inhibition of epithelial $\mathrm{Na}$ channel activity in A6 distal nephron cells. Am J Physiol Renal Physiol 293: F1666-F1677, 2007.

337. Zelko IN and Folz RJ. Extracellular superoxide dismutase functions as a major repressor of hypoxia-induced erythropoietin gene expression. Endocrinology 146: 332-340, 2005.

338. Zhang A, Jia Z, Guo X, and Yang T. Aldosterone induces epithelial-mesenchymal transition via ROS of mitochondrial origin. Am J Physiol Renal Physiol 293: F723-F731, 2007.

339. Zhang N, Komine-Kobayashi M, Tanaka R, Liu M, Mizuno Y, and Urabe T. Edaravone reduces early accumulation of oxidative products and sequential inflammatory responses after transient focal ischemia in mice brain. Stroke 36: 2220-2225, 2005.

340. Zou AP, Li N, and Cowley AW, Jr. Production and actions of superoxide in the renal medulla. Hypertension 37: 547 $553,2001$.

Address correspondence to: Dr. Michael S. Wolin Department of Physiology Renal Research Institute New York Medical College 15 Dana Road Valhalla, NY 10595

E-mail: mike_wolin@nymc.edu

Date of first submission to ARS Central, February 3, 2016; date of acceptance, February 22, 2016.

\begin{tabular}{|c|}
\hline 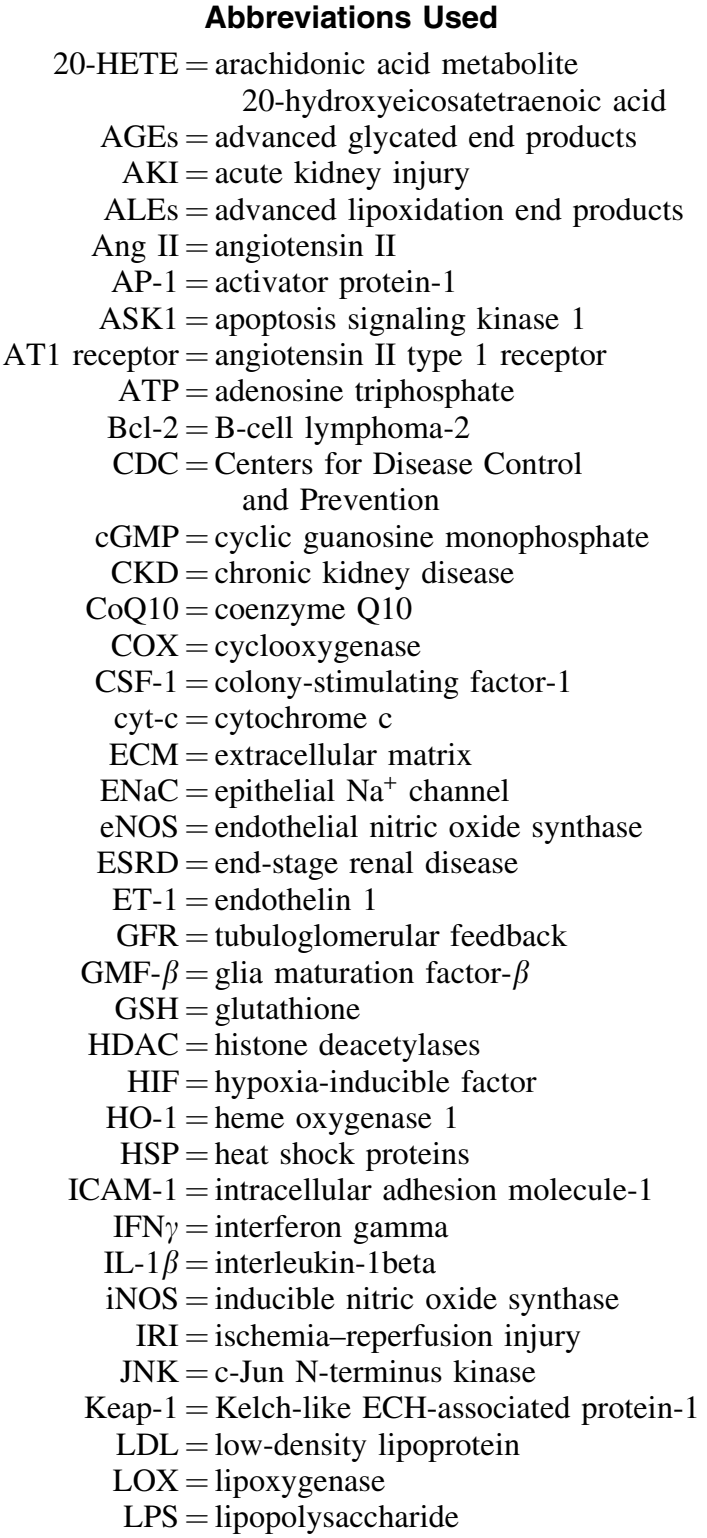 \\
\hline
\end{tabular}




\section{Abbreviations Used (Cont.)}

MAPK $=$ mitogen-activated protein kinase

MCP-1 = monocyte chemoattractant protein 1

MIP-2 = macrophage inflammatory protein-2

MitoQ $=$ mitoquinone mesylate

MitoVit $\mathrm{E}=$ mitochondrial targeted vitamin $\mathrm{E}$

$\mathrm{mTAL}=$ medullary thick ascending limb

$\mathrm{NAC}=\mathrm{N}$-acetylcysteine

$\mathrm{NADPH}=$ nicotinamide adenine dinucleotide phosphate

$\mathrm{NFkB}=$ nuclear factor kappa-light-chainenhancer of activated $B$ cells

NHE3 $=\mathrm{Na}^{+} / \mathrm{H}^{+}$exchanger

NHERF2 $=\mathrm{Na}^{+} / \mathrm{H}^{+}$exchanger regulatory factor

$\mathrm{NKCC} 2=\mathrm{Na}^{+} / \mathrm{K}^{+} / 2 \mathrm{Cl}^{-}$cotransporter

$\mathrm{nNOS}=$ neuronal nitric oxide synthase

$\mathrm{NOX}=\mathrm{NADPH}$ oxidase

$\mathrm{NRF}-1=$ nuclear respiratory factor -1

NRF-2 = nuclear factor E2-related factor

NSAIDs $=$ nonsteroidal anti-inflammatories

PAI-1 = plasminogen activator inhibitor-1

PARP-1 = poly(ADP-ribosyl) polyperase
$\mathrm{PKB}=$ protein kinase $\mathrm{B}$

$\mathrm{PKC}=$ protein kinase $\mathrm{C}$

PTCs $=$ proximal tubular cells

$\mathrm{PTK}=$ protein tyrosine kinases

PTPs $=$ protein tyrosine phosphatases

RAGE $=$ receptor for advanced glycation end products

RANTES $=$ regulated upon activation, normal

$\mathrm{T}$ cell expressed and secreted

RIPK $=$ receptor-interacting protein

$\mathrm{RNS}=$ reactive nitrogen species

$\mathrm{ROS}=$ reactive oxygen species

$\mathrm{RVR}=$ renal vascular resistance

$\mathrm{SOD}=$ superoxide dismutase

Tfam $=$ mitochondrial transcription factor $\mathrm{A}$

TGF- $\beta=$ transforming growth factor beta

$\mathrm{TNF} \alpha=$ tumor necrosis factor alpha

$\operatorname{Trx}=$ thioredoxin

$\mathrm{UCP} 2=$ uncoupling protein-2

VSMCs $=$ vascular smooth muscle cells

$\mathrm{XO}=$ xanthine oxidase 